\title{
Exocyst complex member EXOC5 is required for survival of hair cells and spiral ganglion neurons and maintenance of hearing
}

\author{
Byeonghyeon Lee ${ }^{1,2, a}$, Jeong-In Baek ${ }^{3,9, a}$, Hyehyun Min ${ }^{4}$, Seung-Hyun Bae ${ }^{1}$, Kyeonghye \\ Moon $^{4,6}$, Min-A Kim ${ }^{1,2}$, Ye-Ri Kim ${ }^{1,2}$, Ben Fogelgren ${ }^{7}$, Joshua H. Lipschutz ${ }^{8,9}$, Kyu-Yup \\ Lee $^{10}$, Jinwoong Bok ${ }^{4,5,6,{ }^{*}}$, Un-Kyung Kim ${ }^{1,2,{ }^{*}}$ \\ ${ }^{1}$ Department of Biology, College of Natural Sciences, Kyungpook National University, Daegu \\ 41566, Republic of Korea \\ ${ }^{2}$ School of Life Sciences, BK21 Plus KNU Creative BioResearch Group, Kyungpook National \\ University, Daegu 41566, Republic of Korea \\ ${ }^{3}$ Department of Aroma-applied industry, Daegu Haany University, Gyeongsan 38610, Republic of \\ Korea \\ ${ }^{4}$ Department of Anatomy, Yonsei University College of Medicine, Seoul 03722, Republic of Korea \\ ${ }^{5}$ Otorhinolaryngology, Yonsei University College of Medicine, Seoul 03722, Republic of Korea \\ ${ }^{6}$ BK21PLUS Project for Medical Science, Yonsei University College of Medicine, Seoul 03722, \\ Republic of Korea \\ ${ }^{7}$ Department of Anatomy, Biochemistry, and Physiology, John A. Burns School of Medicine, \\ University of Hawaii at Manoa, Honolulu, Hawaii 96813, United States of America \\ ${ }^{8}$ Department of Medicine, Ralph H. Johnson Veterans Affairs Medical Center, Charleston, South \\ Carolina 29401, United States of America \\ ${ }^{9}$ Department of Medicine, Medical University of South Carolina, Charleston, South Carolina \\ 29425, United States of America \\ ${ }^{10}$ Department of Otorhinolaryngology-Head and Neck Surgery, School of Medicine, Kyungpook \\ National University, Daegu 41944, Republic of Korea
}

\section{Abstract \\ The exocyst, an octameric protein complex consisting of Exoc1 through Exoc8, was first determined to regulate exocytosis by targeting vesicles to the plasma membrane in yeast to mice. In addition to this fundamental role, the exocyst complex has been implicated in other cellular processes. In this study, we investigated the role of the exocyst in cochlear development and hearing by targeting EXOC5, a central exocyst component. Deleting Exoc5 in the otic epithelium}

"Corresponding author: Jinwoong Bok, Ph.D., Department of Anatomy and Otorhinolaryngology, Yonsei University College of Medicine, Seoul 03722, Republic of Korea, TEL: +82-2-2228-0753, FAX: +82-2-365-0700, bokj@yuhs.ac, Un-Kyung Kim, Ph.D., Department of Biology, College of Natural Sciences, Kyungpook National University, Daegu 41566, Republic of Korea, TEL: +82-53-950-5353, FAX: +82-53-939-3066, kimuk@knu.ac.kr.

aThese authors contributed equally to this work.

Conflict of Interest

The authors declare that they have no conflict of interest. 
with widely used Cre lines resulted in early lethality. Thus, we generated two different inner earspecific Exoc5 knockout models by crossing $G f_{i 1}{ }^{C r e}$ mice with $E x o c 5^{f / f}$ mice for hair cell-specific deletion $\left(\mathrm{Gfi}^{\mathrm{Cre} / \mathrm{t}}\right.$;Exoc $\left.5^{\mathrm{f} / \mathrm{f}}\right)$ and by in utero delivery of rAAV-iCre into the otocyst of embryonic day 12.5 for deletion throughout the otic epithelium (rAAV2/1-iCre;Exoc $\left.5^{f / f}\right)$. Gfi ${ }^{C r e / t} ;$ Exoc $^{f / f}$ mice showed relatively normal hair cell morphology until postnatal day 20, after which hair cells underwent apoptosis accompanied by disorganization of stereociliary bundles, resulting in progressive hearing loss. $\mathrm{AAAV} 2 / 1-i C r e ; E x o c 5^{f / f}$ mice exhibited abnormal neurite morphology, followed by apoptotic degeneration of spiral ganglion neurons (SGNs) and hair cells, which led to profound and early-onset hearing loss. These results demonstrate that Exoc5 is essential for the normal development and survival of cochlear hair cells and SGNs, as well as the functional maintenance of hearing.

\section{Keywords}

Exoc5; exocyst; cochlea; spiral ganglion; hearing loss

\section{Introduction}

The exocyst is an octameric protein complex comprising Exoc1 (also known as Sec3 in Saccharomyces cerevisiae), Exoc2 (Sec5), Exoc3 (Sec6), Exoc4 (Sec8), Exoc5 (Sec10), Exoc6 (Sec15), Exoc7 (Exo70), and Exoc8 (Exo84) [1]. It was first identified in budding yeast Saccharomyces cerevisiae where it plays a role in exocytosis of secretory vesicles and polarized membrane growth in developing daughter cells $[1,2]$. Homologs of the eight yeast exocyst subunits (Exoc1-8) have been identified in many multicellular organisms including fungi, plants, insects, and vertebrates; and the structure and function of the exocyst have been shown to be highly conserved throughout the animal kingdom [3-5]. In addition to its basic function in exocytosis, the exocyst has been implicated in a wide range of cellular processes including epithelial polarization [6,7], cell migration [8], neuronal morphogenesis [9], cell cycle progression [10], autophagy [11], and primary ciliogenesis [12].

The assembly and function of the exocyst is regulated by the Arf [13], Rho, Rab, and Ral families of small GTPases. A number of in vitro and in vivo studies in yeast, Drosophila, zebrafish, and mice have shown that small GTPases, including Rho3, Cdc42, Sec4 (Rab8), Rab11, RalA, and RalB, interact with specific exocyst subunits either on transport vesicles or at target sites of the plasma membrane to regulate various aspects of exocyst function $[5,14]$. For example, in yeast, Cdc42, a Rho family GTPase, directly interacts with Sec3, and this interaction is required for targeting the exocyst to the plasma membrane [15]. In renal tubule epithelial cells, Cdc42 interacts and colocalizes with Exoc5, the homolog of yeast sec10, and contributes to ciliogenesis by targeting vesicles carrying ciliary proteins to the primary cilium [16]. Consistently, several in vivo studies have shown that deletion of Cdc42 or Exoc5 causes characteristic ciliopathy phenotypes, such as cystic kidney disease and retinal degeneration $[13,17,18]$. Similarly, Sec4, a Rab family GTPase, interacts with Sec15 and transports vesicles to target sites in yeast, and inactivation of the Sec4 vertebrate homolog, Rab8, in mice has been shown to cause cystic kidney disease and retinal degeneration $[19,20]$. 
Interestingly, some exocyst regulators, such as Cdc42 and Rab8b, have been shown to play an essential role in cochlear development and hearing function [21-23]. Cdc42 is required for normal development as well as maintenance of hair cells and supporting cells, and Cdc42 deficiency causes severe sensorineural hearing loss in mice [21,23]. In addition, Rab8b has been shown to interact with otoferlin, which is essential for synaptic vesicle exocytosis at the ribbon synapse of inner hair cells (IHCs) [24]; mutations in OTOF gene encoding otoferlin lead to autosomal recessive DFNB9 deafness in humans [22]. These reports suggest that exocyst function may also be important for cochlear development and hearing function, but the role of the exocyst in the inner ear has not been explored.

Thus far, several mouse models have been generated that carry knockout alleles of specific exocyst subunits, including Exoc3, Exoc4, Exoc5, and Exoc8; however, all these mice displayed early embryonic lethality, precluding analyses of cochlear development and function [25]. Currently, the only available conditional allele (floxed) is for Exoc5, which is a central component of the exocyst complex and acts as a bridge between transport vesicles and other exocyst subunits [26]. Previous studies using Exoc5 tissue-specific knockout mice have focused on the kidney, showing that inactivation of Exoc5 in the kidney and ureter epithelium causes polycystic kidney disease and ureter obstruction due to abnormal ciliogenesis [17,13]. Given the commonalities in pathogenic mechanisms between the kidney and inner ear [27-29], the exocyst is also expected to play a crucial role in inner ear development and function.

In this study, we examined the role of the exocyst in the inner ear by specifically deleting Exoc5 in otic tissues using two different methods: by crossing Exoc $5^{f / f}$ with $G f i 1^{C r e}$ mice for hair cell-specific deletion, and by in utero delivery of recombinant adeno-associated virus vector carrying improved Cre recombinase (rAAV2/1-iCre) into otocysts of Exoc5 $5^{f / f}$ embryos for deletion in the entire otic epithelium. We observed that inactivation of Exoc5 caused progressive hearing loss that resulted from degeneration of stereocilia, followed by apoptotic hair cell loss, as well as abnormal neuritogenesis and loss of spiral ganglion neurons (SGNs). These results demonstrate that the exocyst plays a crucial role in hearing function by regulating the development and maintenance of hair cells and SGNs.

\section{Materials and Methods}

\section{Animals}

Deletion of Exoc5 exons 7-10 in cochlear hair cells was achieved by mating Exoc5 $5^{f / f}$ mice with $\mathrm{Gfi}_{1}{ }^{\mathrm{Cre} / \mathrm{t}}$ mice, which express $\mathrm{Cre}$ recombinase in developing hair cells (Supplementary figure 1) [17,30]. Deletion of Exoc5 exons 7-10 in the otic epithelium was achieved by in utero delivery of rAAV2/1-iCre into the otocyst at embryonic day (E) 12.5. Rosa26-tdTomato reporter mice were purchased from the Jackson Laboratory (Bar Harbor, ME, USA). All the mouse strains used in this study were on the C57BL/6J genetic background. All animal procedures were conducted in accordance with the Institutional Animal Care guidelines issued by the Committee of Animal Research of Kyungpook National University. 


\section{Recombinant adeno-associated virus (rAAV) and trans-uterine microinjection}

rAAVs containing an inverted terminal repeat from AAV serotype 2 and a capsid from AAV serotype 1 (rAAV2/1) were purchased from Vector Biolabs (Malvern, PA, USA). Prepackaged rAAVs expressing codon-improved $C r e$ recombinase (iCre) along with enhanced green fluorescent protein (eGFP) driven by the CAG2 promoter (rAAV2/1-iCre) were used. The "self-cleavage" of Thosea asigna virus $2 \mathrm{~A}$, a peptide bridge between eGFP and iCre, allows two proteins to be separated after translation. The rAAV2/1 titer was defined as vector genome copies per milliliter $(\mathrm{GC} / \mathrm{mL})$. rAAV2/1 was stored at $-80^{\circ} \mathrm{C}$ and thawed immediately before surgery. Pregnant Exoc $5^{f / f}$ mice were anesthetized on E12.5 with an intramuscular injection of tiletamine-zolazepam $(1.8 \mathrm{mg} / 100 \mathrm{~g})$ and xylazine hydrochloride $(0.7 \mathrm{mg} / 100 \mathrm{~g}) .2 .0 \times 10^{13} \mathrm{GC} / \mathrm{ml}$ of rAAV2/1-iCre was microinjected unilaterally into the left otocyst of E12.5 embryos, in contrast, right otocyst was used by internal control as previously described [31].

\section{In situ hybridization}

Digoxigenin-labeled antisense RNA probes were synthesized using a DIG-RNA labeling kit (Roche, Basel, Switzerland) according to the manufacturer's instructions. The RNA probe for Exoc 5 was generated from mouse Exoc 5 cDNA containing c. 246 to c. 1150 coding regions (NM_207214.3). The synthesized RNA probe was hybridized with the target mRNA for $20 \mathrm{~h}$ at $70^{\circ} \mathrm{C}$, and then the hybridized RNA probes were bound with an anti-digoxigenin antibody conjugated to alkaline phosphatase (Roche) for $12 \mathrm{~h}$ at $4^{\circ} \mathrm{C}$. Gene expression was detected through a reaction with nitro-blue tetrazolium/5-bromo-4-chloro-39-indoly phosphate solution (Roche).

\section{Antibodies}

The primary antibodies used in this study are as follows: rabbit polyclonal anti-Exoc5 (Abcam Inc., Cambridge, MA, USA); rabbit polyclonal anti-Myo7a (Proteus BioSciences, Ramona, CA, USA) and mouse polyclonal anti-Myo7a (Developmental Studies Hybridoma Bank, Iowa City, IA, USA); rabbit polyclonal anti-cleaved Caspase3 (Cell Signaling Technology, Danvers, MA, USA); mouse monoclonal anti-NF200 (Millipore Filter Corporation, Billerica, MA, USA); mouse polyclonal anti-TuJ1 (BioLegend, San Diego, CA, USA); rabbit polyclonal anti-Cre (Novagen, San Diego, CA, USA); anti-Arl13b (gifted from Hyuk-Wan Ko of Dongguk University College of Pharmacy); mouse monoclonal antiAcetylated tubulin (Sigma-Aldrich, St. Louis, MO, USA). The secondary antibodies used for immunofluorescence were Alexa Fluor 405-, 488-conjugated goat anti-mouse IgG and 555- or 568-conjugated goat anti-rabbit IgG (Invitrogen, Waltham, MA, USA). All antibodies were diluted in 5\% normal goat serum (NGS) with $0.1 \%$ Triton X-100 in $1 \mathrm{X}$ PBS (PBS-Tx).

\section{Immunofluorescence and histological analysis}

Inner ears were harvested and fixed with $4 \%$ paraformaldehyde (PFA). The fixed inner ear tissues were embedded in optimal cutting temperature compound (OCT; Leica Microsystems, Nussloch, Germany) or in paraffin. OCT- and paraffin-embedded tissues were serially sectioned at 10 and $6 \mu \mathrm{m}$, respectively, and were then subjected to 
immunofluorescence analysis or hematoxylin-eosin (H\&E) staining. The cryosections were rehydrated in $1 \mathrm{X}$ PBS, whereas paraffin sections were incubated for $1 \mathrm{~h}$ at $65^{\circ} \mathrm{C}$, deparaffinized with xylene, and rehydrated using a graded ethanol series. The tissue sections were permeabilized with PBS-Tx for $30 \mathrm{~min}$ and blocked using a blocking solution containing 5\% NGS in PBS-Tx for $1 \mathrm{~h}$ at room temperature (RT). The sections were then incubated overnight at $4{ }^{\circ} \mathrm{C}$ with primary antibodies. After washing with PBS, the tissue sections were incubated for $1 \mathrm{~h}$ at RT with secondary antibodies. 4'-6-Diamidino-2phenylindole (DAPI, $1 \mu \mathrm{g} / \mathrm{mL}$ ) was used to visualize nuclei. The stained sections were mounted with Fluoromount (Sigma-Aldrich) and sealed with a microscope cover slip (Marienfeld Laboratory, Lauda-Königshofen, Germany). To verify the transduction efficiency of rAAV2/1-iCre, we measured the percentage of iCre-positive cells in the spiral ganglion of Exoc5 $5^{\mathrm{f} / \mathrm{f}}$ and $\mathrm{rAAV} 2 / 1-i C r e ; E x O c 5^{\mathrm{f} / f}$ mice at P0, by counting average number of iCre-positive cells in $100 \mu \mathrm{m}^{2}$ of paraffin section in each turn.

\section{Immunostaining of cochlear whole mounts}

For whole-mount immunostaining of the cochlea, inner ears were dissected out of the temporal bone, and a small opening was made in the oval window of the cochlea before fixation in $4 \%$ PFA in $1 x$ PBS (pH 7.4) overnight at $4^{\circ} \mathrm{C}$. After fixation, Reissner's membrane, the lateral wall, and tectorial membranes were removed, and the remaining tissues were permeabilized by immersion in 5\% Triton X-100 in PBS for 30 min, blocked with blocking solution containing 5\% NGS in PBS for $1 \mathrm{~h}$ at RT, and stained overnight at $4^{\circ} \mathrm{C}$ with primary antibodies. Next day, the specimens were washed with PBS and incubated with secondary antibodies for $2 \mathrm{~h}$ at RT. The specimens were visualized using a Zeiss LSM 700 confocal microscope (Zeiss, Oberkochen, Germany). Zen 2012 software (Zeiss) was used for image acquisition, and 3D reconstruction was performed using Imaris 7.2.3 software (Bitplane, Zurich, Switzerland). To examine the transduction efficiency of rAAV2/1-iCre, we measured the percentage of GFP-positive cells in organ of Corti of Exoc $5^{f / f}$ and rAAV2/1-iCre;EXoc $5^{f / f}$ mice at postnatal day (P) 0 , by counting average number of GFP-positive hair cells of cochlear whole mounts in $200 \mu \mathrm{m}$ region of each turn.

\section{Auditory brainstem response (ABR) measurement}

Mouse auditory function was assessed by measuring ABR with an ABR workstation (System 3; Tucker Davis Technology (TDT Inc., Alachua, FL, USA) as previously described [31]. Auditory function was measured with click stimuli and tone burst sound frequencies of 8,16 , and $32 \mathrm{kHz}$, and acoustic thresholds of sound pressure level (SPL) were determined using BioSigRP software (TDT Inc.). All results were obtained from at least three mice.

\section{Scanning electron microscopy (SEM) analysis}

Scanning electron micrographs of inner ears were obtained as previously described [32]. Briefly, inner ear tissues were fixed with $0.1 \mathrm{M}$ sodium cacodylate buffer ( $\mathrm{pH} 7.4)$ containing 2\% PFA and 2.5\% glutaraldehyde, dried using a critical point drier (HCP-2; Hitachi, Tokyo, Japan), and coated with platinum by a sputter coater (E1030; Hitachi). The coated specimens were examined under a cold-field emission scanning electron microscope (SU8220; Hitachi) operated at 5 or $10 \mathrm{kV}$. Average number of inner and outer hair cells 
which had stereocilia was measured in $60 \mu \mathrm{m}$ length at each turn of organ of Corti of Exoc5 ${ }^{f / f}$ and Gfi1-Cre;Exoc5 ${ }^{f / f}$ mice, at P20 and P50.

\section{Analysis of positional deviation of kinocilia}

The cochleae of Exoc $5^{f / f}$ and rAAV2/1-iCre;Exoc $5^{f / f}$ mice at P0 were labeled with phalloidin, anti-Arl13b (or anti-Acetylated tubulin) antibody, and anti-iCre antibody by whole mount immunostaining, and were imaged at basal (10\%), middle (50\%), and apical (90\%) regions of the cochlea using confocal microscopy (LSM780; Zeiss). A line connecting from the center of the hair cell to the base of kinocilia and another line connecting the centers of three adjacent hair cells were drawn, and the angle between the two lines was measured using the ImageJ (NIH, Rockville, USA) angle measurement tool. The base of kinocilia were determined as previously described [33]. If a hair cell had a normally localized kinocilium, the angle between the two lines yielded 90 degrees, which was considered as 0 degree. Deviations from the right angle were measured as deviation degrees.

\section{Terminal deoxynucleotidyl transferase dUTP nick end labeling (TUNEL) assay}

To assess apoptotic cell death in the inner ear, we evaluated DNA fragmentation using the TUNEL assay according to the manufacturer's protocol (Promega, Madison, WI, USA). Paraffin-embedded inner ear sections were performed with deparaffinization and rehydration. They were then permeabilized with $0.1 \%$ Triton X-100 and $0.1 \%$ sodium citrate in distilled water for $20 \mathrm{~min}$ at RT, and stained with TUNEL working solution for $1 \mathrm{~h}$ at $37^{\circ} \mathrm{C}$, without light. The specimens were mounted on glass slides using Fluoromount and visualized using a Zeiss Axio Imager A2 fluorescence microscope (Zeiss).

\section{Statistical analyses}

Statistical analyses were performed using 2-tailed Student's $t$-tests; $P<0.05$ was considered statistically significant. The data were analyzed by comparing treated and untreated contralateral structures, or by comparing treated and control mice.

\section{Results}

\section{Exoc5 is broadly expressed in the developing and mature mouse cochlea}

The spatial and temporal expression patterns of Exoc5 in the mouse inner ear were examined by in situ hybridization and immunofluorescence analysis at P0 and P20 (Fig. 1). In the P0 cochlea, Exoc5 mRNA and proteins were broadly expressed in the sensory and non-sensory epithelia surrounding the scala media, as well as in the SGNs (Fig. 1A-1I). At P20, when hearing is functional, EXOC5 was broadly expressed in the cochlear sensory and nonsensory tissues, including the hair cells and supporting cells such as Deiters' cells, inner border cells, inner phalangeal cells, inner and outer pillar cells, and Claudius cells in the organ of Corti (Fig. 1L and 1M), SGNs (Fig. 1N and 1O), Reissner's membrane, and the fibrocytes of the lateral wall (Fig. 1J and 1K). The specificity of the Exoc5 antibody was validated in $\mathrm{ExOC}^{\mathrm{fff}}$ and $\mathrm{Gfi}^{\mathrm{Cr} / \mathrm{t}} ; \mathrm{ExOC}^{\mathrm{f} / \mathrm{f}}$ mice by immunofluorescence at P20, and haircell specific Exoc5 knockout in $G f i 1^{C r e /+}$;Exoc $5^{f / f}$ cochlea was confirmed (supplementary 
figure 2). The continuous and broad expression levels of EXOC5 in the mouse cochlea suggest that the exocyst may play an important role in cochlear development and function.

\section{Exoc5 deficiency in hair cells results in progressive hearing loss}

To examine the role of EXOC5 in inner ear development, we first attempted to delete Exoc5 in the entire otic epithelium by crossing Exoc $5^{f / f}$ mice with either Pax2-Cre or Foxg1 Cre mice $[34,35]$. However, only cystic inner ear structures were observed in these conditional knockout mice, suggesting a crucial role of Exoc5 in early specification or maintenance of the inner ear tissues. Since the absence of recognizable inner ear structures in these mutants precluded further examination, we thus explored the role of EXOC5 more specifically in hair cells at later developmental stages by crossing Exoc $^{f / f}$ mice with $\mathrm{Gfi} 1^{\mathrm{Cre} / \mathrm{t}}$ mice, which induce Cre-mediated recombination in the developing hair cells in the cochlea starting at E15.5 [30]. We confirmed the Cre recombination activity of $\mathrm{Gfil}^{\mathrm{Cr} / \mathrm{t}}$ mice by crossing them with Rosa26-tdTomato reporter mice, which showed specific expression of red fluorescence in hair cells [36,37] (Supplementary figure 1).

We first examined whether hair cell-specific deletion of Exoc 5 would cause functional deficits of hair cells by measuring hearing thresholds. Gfi ${ }^{C r e / t} ; E x o c 5^{f / f}$ mice were subjected to ABR testing with a broadband click stimulus and with frequency-specific stimuli at $8 \mathrm{kHz}, 16 \mathrm{kHz}$, and $32 \mathrm{kHz}$ from P20 to P50 (Fig. 2). At P20, when mouse hearing ability is sufficiently matured, $\mathrm{Gfi}^{\mathrm{Cre} / \mathrm{t}}$,Exoc5 ${ }^{f / f}$ mice exhibited significantly higher hearing thresholds ( $\leq 20 \mathrm{~dB}$ SPL threshold shift) in click, and all frequency tone burst stimuli tested, than Exoc5 ${ }^{f / f}$ controls (Fig. 2). The ABR thresholds of $\mathrm{Gfi}^{\mathrm{Cre} / \mathrm{t}}$;Exoc5 ${ }^{\mathrm{f} / \mathrm{f}}$ mice rapidly increased with age, and hearing function was severely impaired for all frequencies by P50 ( $\geq$ $50 \mathrm{~dB}$ SPL threshold shift), which is a typical pattern of progressive hearing loss observed in humans. These results indicate that Exoc5 deficiency in hair cells causes severe progressive sensorineural hearing loss in mice, suggesting a crucial role of Exoc5 in hair cell development or function.

\section{Progressive degeneration of stereocilia and hair cells in Gfi1 ${ }^{\mathrm{Cre} /+} ; \mathrm{ExOc}^{f / f}$ mice}

To determine the cause of the progressive hearing loss observed in $\mathrm{Gfil}^{\mathrm{Cre} / \mathrm{t}} ; \mathrm{Exoc}^{\mathrm{f} / \mathrm{f}}$ mice, we first compared the histological characteristics of the cochlea of Exoc $5^{f / f}$ and Gfi $^{C r e / t}$;EXoc5 ${ }^{f / f}$ mice at P20 and P50 using H\&E staining (Fig. 3). No noticeable difference was observed in the cochlear histology between Exoc5 $5^{f / f}$ and Gfi ${ }^{C r e / t}$;Exoc $5^{f / f}$ mice at P20 (Fig. 3A-3F), suggesting that the cochlea develops in a relatively normal fashion in $\mathrm{Gfi}^{\mathrm{Cre} / \mathrm{A}} ; \mathrm{ExOC} \mathrm{F}^{\mathrm{fff}}$ mice. In contrast, we observed degeneration of outer hair cells (OHCs) in $\mathrm{Gfil}^{\mathrm{Cre} / \mathrm{t}}$;EXoc $5^{\mathrm{f} / \mathrm{f}}$ mice at P50, while the IHCs remained intact (Fig. 3K-3L). No distinguishable difference was observed in other cochlear regions, such as the spiral ganglion, spiral limbus, Reissner's membrane, and lateral wall (Fig. 3I-3J).

We next examined the stereociliary bundles of hair cells using SEM (Fig. 4). At P20, overall morphologies of the organ of Corti of $\mathrm{Gfi}^{\mathrm{Cre} / \mathrm{t}} ; \mathrm{ExOC}^{\mathrm{f} / \mathrm{f}}$ mice were relatively normal and were comparable to those of Exoc $5^{f / f}$ mice, displaying a typical single row of IHCs and three rows of OHCs with crescent-shaped and ' $\mathrm{W}$ '-shaped arrangements of stereociliary bundles, respectively (Fig. 4A-4F). However, at P50, severe degeneration of hair cells 
occurred in Gfi $^{\mathrm{Cre} / \mathrm{t}}$;EXoc $5^{\mathrm{ff/}}$ mice (Fig. 4G-4L). Although staircase-pattern stereociliary arrangements were collapsed in both IHCs and OHCs, OHCs appeared more severely affected than IHCs, which mostly retained their stereociliary bundles (Fig. 4G-4L). In addition, these abnormalities were more severe in the basal turn compared with those in the middle and apical turns, showing that almost all OHCs lost their stereocilia in the basal turn, while gradually more hair cells retained their stereocilia towards the apical turn (Fig. 4J$4 \mathrm{~L}$ ). The quantitation analysis of the remaining hair cells at each turn showed a statistical significance of this phenomenon, supporting the results of SEM (Supplementary figure 3). These histological and morphological deficits of $\mathrm{Gfi}_{1}{ }^{\mathrm{Cre} / \mathrm{A}} ; \mathrm{ExOc}^{\mathrm{ff} / \mathrm{f}}$ mutant cochlea were consistent with the functional deficits exhibiting progressive hearing loss. These results suggest that EXOC5 plays a crucial role in the maintenance of stereociliary bundles of cochlear hair cells.

\section{Inactivation of Exoc5 by in utero injection of rAAV2/1-iCre into the Exoc $5^{f / f}$ otocysts}

Our results from Gfi $^{\mathrm{Cre} / \mathrm{t}} ; \mathrm{EXOC}^{\mathrm{f} / \mathrm{f}}$ mice demonstrated that EXOC5 plays a crucial role in maintenance of hair cells and hearing function, but this model is limited in the study of the role of Exoc5 in developmental aspects of the cochlea due to the relatively late onset of Gfi1 expression [30]. Although Pax2-Cre or Foxg $1{ }^{C r e}$ mice have been often used to inactivate specific genes in the otic epithelium from placodal stages [38], we could only find a small cyst-like structure of the inner ear in Pax2-Cre;Exoc5 ${ }^{f / f}$ or Foxg $1^{C r e / t} ;$ Exoc5 ${ }^{f / f}$ mutant embryos, which precluded further analysis of inner ear development. To overcome this limitation of the conventional Cre/loxP system using Cre mice, we deleted Exoc5 in the developing otocyst using a viral-mediated gene delivery system. We used a rAAV2/1-iCre. rAAV2/1-iCre was injected in utero into the developing otocyst of E12.5 Exoc5 $5^{f / f}$ embryos (Supplementary figure 4A).

To verify the safety and feasibility of rAAV injection into the otocyst via a trans-uterine approach, we delivered rAAV2/1-iCre directly into the otocyst of wild-type mouse embryos at E12.5 and evaluated inner ear morphology and hearing function at P20. No significant differences in ABR thresholds were observed between the rAAV2/1-iCre-injected and noninjected inner ears ( $n=5$ for each group, $P>0.05$; Supplementary figure 4B). Consistently, H\&E stained sections of the rAAV2/1-iCre injected inner ear did not show any histological defects compared with those of non-injected control ears (Supplementary figure 4C). These results demonstrated that our virus injection system does not cause any detectable physiological or functional damage in the injected inner ears.

We next verified transduction efficiency of the in utero injected rAAV2/1-iCre in the inner ear by immunostaining at $\mathrm{P} 0$, to confirm the effectiveness of this mosaic knockout model (Supplementary figure 5). In whole-mount immunostaining of the organ of Corti, iCretransduced hair cells were labeled with GFP, and the result showed that at least $80 \%$ of hair cells are GFP-positive at each turn (Supplementary figure 5A-5B). This high transduction efficiency was also found in SGNs by detecting iCre-positive cell bodies of SGNs (Supplementary figure 5C-5D). Thus, we could expect that wild-type Exoc5 expression might be efficiently suppressed in the inner ears of $\mathrm{rAAV} 2 / 1-i C r e ; E x o c 5^{f / f}$ mice. 


\section{Profound and early-onset hearing loss in rAAV2/1-iCre;Exoc5 $5^{f / f}$ mice}

The auditory function of rAAV2/1-iCre;Exoc5 ${ }^{f / f}$ mice was determined by the ABR test at P20 (Fig. 5). While the non-injected Exoc5 ${ }^{f / f}$ mice had normal hearing function, the virusinjected rAAV2/1-iCre;Exoc5 ${ }^{f / f}$ mice exhibited severe hearing impairments (Fig. 5).

Approximately 50 60 dB shifts of the ABR thresholds were detected for click stimuli, as well as tone burst stimuli, at all frequencies tested (8, 16, and $32 \mathrm{kHz}$ ) (Fig. 5). The hearing impairment in rAAV2/1-iCre;EXoc $5^{f / f}$ mice began much earlier than those of $\mathrm{Gfi}^{\mathrm{Cre} / \mathrm{t}}$ :Exoc $5^{f / f}$ mice, which only had mild hearing loss with approximately 10 20 dB threshold shifts at P20, though they exhibited profound hearing loss at P50 (Fig. 2).

\section{Early-onset hair cell degeneration in rAAV2/1-iCre;Exoc $5^{f / f}$ mice}

The early-onset hearing loss exhibited by rAAV2/1-iCre;Exoc $5^{f / f}$ mice suggested a crucial role of Exoc5 in the development or survival of hair cells and SGNs. We thus examined the stereociliary bundles of hair cells using SEM at P20 (Fig. 6). Unlike the relatively normal

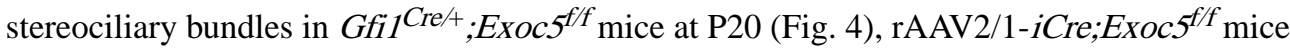
showed severe degeneration of stereociliary bundles, with the remaining hair cells displaying sparse and irregular arrangements on a bumpy apical surface of the organ of Corti (Fig. 6D$6 \mathrm{~F})$. Similar to those of $\mathrm{Gfi}_{1} \mathrm{Cre}^{\mathrm{A}} ; \mathrm{Exoc}^{\mathrm{ff} / \mathrm{f}}$ mice, OHCs were more severely affected than IHCs in rAAV2/1-iCre;Exoc $5^{f / f}$ mice (Fig. 6D-6F). However, the varying severity of hair cell degeneration along the cochlear duct seen in $\mathrm{Gfil}^{\mathrm{Cre} / \mathrm{t}}$;EXoc $5^{\mathrm{f} / \mathrm{f}}$ mice was not observed in rAAV2/1-iCre;Exoc $5^{f / f}$ mice, in which the degeneration occurred throughout the cochlear turns (Fig. 6D-6F). This result is consistent with the severe hearing loss of rAAV2/1$i C r e ; E x o c 5^{f / f}$ mice at all frequencies at P20.

Since hair cell degeneration and hearing loss were evident at P20, we performed histological analysis of rAAV2/1-iCre;Exoc $5^{f / f}$ inner ears from earlier postnatal days, including P8, P15, and P20 (Fig. 7). The sensory epithelium of the rAAV2/1-iCre;Exoc5 ${ }^{f / f}$ cochlea already appeared abnormal at $\mathrm{P} 8$, exhibiting a more compact and thinner epithelial structure compared with that of the non-injected Exoc $5^{f / f}$ cochlea (Fig. 7C-7F). The abnormalities of the sensory epithelia were more severe at P15 and P20, with OHCs more affected than IHCs, consistent with the SEM results (Fig. 6D-6F, 7K-7N and 7S-7V).

In the kidney, Exoc5 deficiency caused abnormal ciliogenesis, which resulted in cystic kidney disease, a characteristic phenotype of ciliopathies [13]. We thus asked if the degeneration of stereociliary bundles and hair cell loss was due to abnormal ciliogenesis in the organ of Corti. We stained the organ of Corti of rAAV2/1-iCre;Exoc $5^{f / f}$ mice with an anti-Arl13b or anti-Acetylated tubulin antibodies to visualize kinocilia, the primary cilia of the hair cells, and with phalloidin to stain stereocilia (Supplementary figure 6). We observed that kinocilia were present in all the hair cells including iCre-positive cells of rAAV2/1iCre;Exoc5 ${ }^{f / f}$ cochlea, similar to those in Exoc5 $5^{f / f}$ cochlea, indicating that ciliogenesis is not affected by Exoc5 deficiency in the cochlea. The locations of kinocilia in each hair cell were generally normal except for a few IHCs in the middle turn of rAAV2/1-iCre;Exoc $5^{f / f}$ cochlea compared with $E x o c 5^{f / f}$ cochlea. Consistently, we observed a few extra hair cells in the middle turn of rAAV2/1-iCre;Exoc $5^{f / f}$ cochlea. These extra hair cells tend to show abnormal stereociliary morphologies with deviated kinociliary locations (Supplementary figure 6). In 
total, although approximately $60-80 \%$ of hair cells in the rAAV2/1-iCre;Exoc $5^{f / f}$ were deficient by $i C r e$ transduction, less than $20 \%$ of iCre-positive hair cells exhibited defective ciliary bundle. These results show that, unlike the kidney, primary ciliogenesis is unaffected by Exoc5 deficiency in the cochlea, and suggests that the degeneration of stereociliary bundles and hair cells in rAAV2/1-iCre;Exoc $5^{\text {f/f }}$ cochlea was probably not due to abnormal ciliogenesis or planar cell polarity.

\section{Abnormal neurite morphology and degeneration of SGNs in rAAV2/1-iCre;Exoc5 $5^{f / f}$ mice}

We also observed from the histological analyses that SGN degeneration was already evident at P8, with sparser neuronal cell populations in rAAV2/1-iCre;Exoc $5^{f / f}$ cochlea compared with those in non-injected ears (Fig. $7 \mathrm{G}$ and $7 \mathrm{H}$ ). These phenotypes became more severe at P15 and P20 (Fig. 7O, 7P, 7W, and 7X), suggesting that EXOC5 is required for the maintenance of SGNs in the cochlea.

Previous studies have suggested that the exocyst complex plays a role in neurite outgrowth by mediating neuronal vesicle trafficking [39]. We thus examined the radial fibers of developing SGNs at P0 and P9 with whole-mount immunostaining of the cochlea and examining 3D-reconstructed images (Fig. 8). At P0, the neuronal radial fibers of the spiral ganglia were less densely packed (Fig. 8A and 8B, arrowheads) and were much thinner near the IHCs in rAAV2/1-iCre;Exoc $5^{f / f}$ mice than in Exoc $5^{f / f}$ mice (Fig. 8C and 8D, brackets). At P9, the innervation of the spiral ganglion neurites was even more severely affected in the rAAV2/1-iCre;EXoc $5^{f / f}$, with misrouted and swollen neuronal fibers near IHCs (Fig. 8E and $8 \mathrm{~F})$. Together, these results suggest that EXOC5 is important for proper projection of the neuronal fibers of the SGNs and SGN survival.

\section{Exoc5 deficiency leads to apoptotic cell death in the sensory epithelia and spiral ganglia}

We next examined whether the degeneration of hair cells and SGNs caused by Exoc5 deficiency was due to apoptosis using activated Caspase3 immunostaining (Fig. 9) and TUNEL assays (Supplementary figure 7). Our functional and morphological analyses showed that cellular degeneration and hearing loss of rAAV2/1-iCre;Exoc $5^{f / f}$ cochlea were obvious at P20, while Gfi $^{C r e / t} ;$ Exoc $^{f / f}$ cochlea showed progressive hearing loss after P20. Thus, we examined apoptotic cell death at P15 for rAAV2/1-iCre;Exoc $5^{f / f}$ cochlea and at P30 for Gfi $^{C r e / 4}$;Exoc ${ }^{f / f}$ cochlea. Activated Caspase3- or TUNEL-positive cells were greatly increased in the sensory epithelium in $\mathrm{Gfi}^{\mathrm{Cre} / \mathrm{t}} ; \mathrm{ExOC}^{\mathrm{ff/}}$ mice compared with Exoc $^{f / f}$ mice at P30 (Fig. 9A; Supplementary figure 7). Similarly, the population undergoing apoptotic cell death increased in the sensory epithelium and spiral ganglia in the rAAV2/1-iCre;EXoc5 $5^{f / f}$ mice at P15 (Fig. 9B; Supplementary figure 7). These results suggest that EXOC5 plays an important role in hearing function by preventing hair cell and SGN apoptosis.

\section{Discussion}

In this study, we examined the role of the exocyst complex in hearing function by analyzing Exoc5-deficient mice generated by two different strategies. Hair cell-specific deletion of Exoc5 with a conventional Cre/loxP system caused disorganization of stereociliary bundles 
followed by hair cell loss, resulting in progressive hearing loss. Knockdown of Exoc5 in the otic epithelium using in utero gene delivery (rAAV2/1-iCre;Exoc $5^{f / f}$ ) resulted in hair cell loss, abnormal neuritogenesis and degeneration of SGNs, leading to early-onset hearing loss. These results demonstrate that the exocyst plays essential roles in hearing by regulating the development and maintenance of hair cells and SGNs.

\section{Role of Exoc5 in hair cell survival}

Our results showing increased active Caspase3- and TUNEL-positive cells indicate that hair cell degeneration caused by Exoc5 deficiency is due to apoptosis. Several studies have demonstrated that the exocyst is associated with apoptotic pathways. In Drosophila, the exocyst promotes sensory cell survival by counteracting c-Jun N-terminal Kinase (JNK)dependent apoptosis through a direct interaction between Exoc2 (Sec5) and HPK1/GCK-like kinase, a JNK signaling activator [40]. In malignant peripheral nerve sheath tumors, Exoc3 (Sec6) and Exoc4 (Sec8) have been demonstrated to inhibit apoptosis by regulating transcription of the anti-apoptotic proteins Bcl-2 and Mcl-1 [41]. In addition, Exoc5 (Sec10)-knockdown in Madin-Darby canine kidney cells and conditional knockout of Sec10 in the mouse kidney enhanced sensitivity to apoptotic stimuli, resulting in an increased rate of apoptotic cell death, likely through repression of primary ciliogenesis [42]. How EXOC5 deficiency leads to hair cell apoptosis in the cochlea is currently unclear. However, unlike the kidney in which EXOC5 deficiency caused abnormal ciliogenesis and planar cell polarity, which renders the renal cells more sensitive to apoptotic stimuli [42], ciliogenesis and planar cell polarity were unaffected in hair cells in EXOC5 mutant cochlea, suggesting that the mechanisms leading to EXOC5 deficiency-induced apoptosis is different between hair cells and renal cells. Further investigation is required to understand how EXOC5 inhibits apoptosis in hair cells.

Interestingly, hair cell loss caused by EXOC5 deficiency predominantly affects OHC; stereociliary disarrangement and degeneration were more prominent and occurred earlier in OHCs than IHCs in Exoc5 mutants. Similar patterns of OHC-dominant defects have been reported in several mouse models. In particular, lack of tight junction (TJ) proteins, such as claudin 14 [43], claudin 9 [44], occludins [45], and tricellulins [46], led to pronounced loss of OHCs with collapsed cellular arrangement. In the cochlea, TJs are important for maintaining selective permeability to specific ions and molecules between endolymphatic and perilymphatic compartments, which is crucial for generating the endocochlear potential required for normal hearing [47]. TJ abnormalities cause endolymph leakage, altering the fluidic microenvironment surrounding OHCs, resulting in prolonged depolarization that leads to cell death [48]. In contrast, IHCs are heavily surrounded by supporting cells and are thus less sensitive to the environmental changes caused by TJ abnormalities [46,49]. Since the exocyst complex is also localized at TJs and plays an essential role in the establishment of apical junctional complexes [12,50,51], the OHC-dominant loss caused by EXOC5 deficiency may be associated with abnormal formation or maintenance of TJs in hair cells.

Another example of predominant OHC loss has been reported in mice lacking 14-3-3eta, which is encoded by the $Y$ whah gene [39]. The 14-3-3 proteins have chaperone activity and bind various phosphorylated proteins to regulate their subcellular localization, stability, 
activity, or protein-protein interactions [52]. Interestingly, 14-3-3 controls exocyst function by regulating the activity of an exocyst regulator, Ral GTPases, in 293T cells [53]. The regulation of exocyst function by 14-3-3 has also been observed in filamentous fungi and yeast [54]. Thus, it is possible that the OHC-dominant loss caused by the lack of 14-3-3eta in $Y$ whah null mutants is due to abnormal exocyst function. Together, these results suggest that EXOC5 may promote hair cell survival via multiple mechanisms.

\section{Role of Exoc5 in SGN development and survival}

Previous research has shown that neurite outgrowth is one of the developmental processes regulated by the exocyst. In Drosophila, Exoc2 (Sec5) mutants fail to initiate neurite outgrowth due to impaired trafficking of newly synthesized proteins to the membrane [55]. In cultured hippocampal neurons, the Exoc3 and Exoc4 are localized to the growth cones or tips of growing neurites, and induce membrane fusion and surface expansion to support polarized neurite outgrowth [56]. The requirements of other exocyst subunits, including Exoc5, Exoc7, or Exoc8, in polarized neurite outgrowth and branching have also been demonstrated in PC12 cells and cultured cortical neurons [9,57]. Consistently, the peripheral radial fibers of SGNs in the cochlea are less compact in rAAV2/1-iCre;Exoc $5^{f / f}$ mice than in controls at P0, suggesting that EXOC5 also plays a role in normal neuritogenesis in SGNs. Previous studies have shown that the exocyst regulates polarized neurite growth by interacting with Par complexes or microtubules [9]. Whether EXOC5 uses similar mechanisms to regulate neurite outgrowth in SGNs requires further study.

We also observed swollen neuronal endings near IHCs and degeneration of SGN cell bodies in rAAV2/1-iCre;Exoc $5^{f / f}$ cochlea at P8-9. Phenotypes similar to the swelling SGN nerve terminals have been reported in some pathogenic conditions, such as noise-induced hearing loss and peripheral tinnitus as well as in Wbp2-deficient cochlea [58,59]. These conditions are associated with excitotoxicity caused by abnormal glutamate release from hair cells to SGN postsynaptic endings [60]. Neurotransmitters such as glutamate are released by exocytosis in which the SNARE complex plays a role by regulating the docking and fusion of synaptic vesicles with the plasma membrane [61]. Since the exocyst complex is involved in SNARE-mediated exocytosis [62], the dysregulation of vesicle exocytosis caused by Exoc5 deficiency in hair cells may potentially cause swollen nerve endings and subsequent degeneration of SGNs. Consistent with this idea, disrupted glutamate release from hair cells in mice lacking Vglut3, which mediates the regulated exocytosis of glutamate, results in degeneration of SGNs, suggesting an important role for the regulated exocytosis of glutamate by hair cells in SGN survival [63]. However, unlike rAAV2/1-iCre;Exoc $5^{f / f}$ mice, we did not observe obvious SGN degeneration in $\mathrm{Gfi}^{\mathrm{Cre} / \mathrm{t}}$;EXoc $5^{\mathrm{f} / \mathrm{f}}$ mice, suggesting that abnormal exocytosis in hair cells does not directly cause SGN degeneration. Thus, the SGN degeneration observed in rAAV2/1-iCre;Exoc $5^{f / f}$ cochlea more likely results from EXOC5 deficiency in SGNs rather than indirectly from abnormal exocyst function in hair cells. Although hair cell death is another potential underlying mechanism of SGN degeneration, this proposed mechanism does not seem to contribute, since SGN degeneration occurred earlier than hair cell death in rAAV2/1-iCre;Exoc $5^{f / f}$ cochlea. How EXOC5 supports SGN survival also requires further study. 


\section{Complementary knockout strategies to fully understand EXOC5 functions in cochlea}

To overcome the limitations of whole body knockouts to study gene function in specific tissues or organs, conditional knockout techniques using Cre/loxP recombination have been used extensively and successfully. However, even in spatially and temporally controlled manners, gene deletion can lead to early lethality if the expression domain of Cre recombinase is not strictly restricted, and the target gene is essential for animal survival. To examine the role of EXOC5 in inner ear development and function, we first used two widely utilized Cre lines, Pax2-Cre transgenic and $\mathrm{Foxg}_{1} \mathrm{Cre}^{\mathrm{Ce}}$ knock-in mice [34,35]. Unfortunately, both $\mathrm{Foxg} 1^{\mathrm{Cre} / \mathrm{t}} ; \mathrm{Exoc5}^{\mathrm{f} / \mathrm{f}}$ and $\mathrm{Pax} 2-\mathrm{Cre} ; \mathrm{ExOC}^{\mathrm{f} / \mathrm{f}}$ mice succumb to early embryonic lethality, and their inner ears were barely detected, exhibiting only cystic structures, which is probably due to the early and relatively wide expression of Foxg1 and Pax2. The cystic inner ear phenotypes of these mutants clearly demonstrated the necessity of EXOC5 in early stages of otic specification, but we were unable to investigate the role of Exoc5 in developing and mature cochlea, and in hearing.

Thus, we used $\mathrm{Gfi} 1^{\mathrm{Cre} / \mathrm{t}}$ mice to specifically delete Exoc5 in developing hair cells [30]. Although we still observed neonatal lethality in approximately $50 \%$ of $\mathrm{Gfi}^{\mathrm{Cre} / \mathrm{t}} ; \mathrm{Exoc}^{\mathrm{f} / \mathrm{f}}$ newborn mice, we managed to examine hair cell differentiation, survival, and function using the surviving pups. However, our expression studies indicate broad expression of Exoc5 in the cochlea, including the organ of Corti and SGNs. Since conventional Cre/loxP techniques had limitations for thorough analyses of the function of EXOC5 in the cochlea, we used a viral gene delivery system that can induce expression of Cre recombinase in specific target tissues, leading to tissue-specific Cre/loxP-mediated gene deletion [64]. We introduced the rAAV2/1-iCre vector by in utero delivery into the otic vesicle at E12.5 to avoid the cystic inner ear phenotypes caused by the early recombinase activity of $\mathrm{Pax}_{2} \mathrm{Cre}$ and $\mathrm{Foxg} 1^{\mathrm{Cre}}$ mice. Although this delivery system is a mosaic knockout strategy, it greatly enhanced survival of knockout mice and allowed us to investigate cochlear abnormalities and the resulting hearing loss phenotypes caused by Exoc5 deficiency. Combination of these two different knockout strategies, Gfi ${ }^{C r e /+} ;$ Exoc5 $^{f / f}$ and rAAV2/1-iCre;Exoc5 ${ }^{f / f}$, allowed us to complement the drawbacks of each knockout technique, and the consistency of the defective phenotypes observed in the two different knockout models strengthens the reliability of our finding that Exoc5 function is required for the maintenance and function of cochlear hair cells and SGNs.

In summary, we report that Exoc5 deficiency results in disorganized stereociliary bundles in hair cells and defective neurite outgrowth of SGNs, followed by apoptosis of both cell types, eventually leading to progressive hearing loss. This study is the first to demonstrate the importance of Exoc5 in the maintenance of structural integrity, and in the hearing function of the cochlea. In addition, our complementary inner ear-specific gene deletion strategies using conventional and viral vector-mediated Cre/loxP techniques will be useful in studies of gene functions contributing to cochlear development and function that might otherwise be hampered by early lethality or developmental arrest.

\section{Supplementary Material}

Refer to Web version on PubMed Central for supplementary material. 


\section{Acknowledgement}

We thank Dr. Lin Gan for Gfil Cre/+ mice. The UAB P30 Hepatorenal Fibrocystic Disease Core Center is gratefully acknowledged for generating the Exoc5f/f mice. This work was supported by the National Research Foundation of Korea Grant 2014M3A9D5073865 (to J.B. and U.K.K.), 2017R1C1B2009705 (to J.I.B), and 2017R1A2B3009133 (to J.B.), and by the Yonsei University Future-leading Research Initiative (2015-22-0058). This work was also supported in part by grants from the VA (Merit Award I01 BX000820 to J.H.L) and NIH (P30DK074038 to J.H.L) in the United States of America.

\section{Abbreviations}

IHCs

SGNs

$\mathbf{E}$

rAAV

rAAV2/1

iCre

eGFP

GC/mL

NGS

PBS-Tx

PFA

OCT

H\&E

RT

DAPI

ABR

$\mathbf{P}$

TDT

SPL

SEM

RT-PCR

TUNEL

OHCs inner hair cells

spiral ganglion neurons

embryonic day

recombinant adeno-associated virus

AAV serotype 2 and a capsid from AAV serotype 1

codon-improved Cre recombinase

enhanced green fluorescent protein

genome copies per milliliter

normal goat serum

$0.1 \%$ triton $\mathrm{X}-100$ in $1 \mathrm{X}$ PBS

paraformaldehyde

optimal cutting temperature compound

hematoxylin-eosin

room temperature

4'-6-Diamidino-2-phenylindole

auditory brainstem response

postnatal day

Tucker Davis Technology

sound pressure level

scanning electron microscopy

reverse-transcription polymerase chain reaction

Terminal deoxynucleotidyl transferase dUTP nick end labeling

outer hair cells 


$\begin{array}{ll}\text { JNK } & \text { c-Jun N-terminal Kinase } \\ \text { TJ } & \text { tight junction }\end{array}$

\section{References}

1. TerBush DR, Maurice T, Roth D, Novick P (1996) The Exocyst is a multiprotein complex required for exocytosis in Saccharomyces cerevisiae. The EMBO journal 15 (23):6483-6494 [PubMed: 8978675]

2. Zajac A, Sun X, Zhang J, Guo W (2005) Cyclical regulation of the exocyst and cell polarity determinants for polarized cell growth. Molecular biology of the cell 16 (3):1500-1512 [PubMed: 15647373]

3. Hsu SC, Ting AE, Hazuka CD, Davanger S, Kenny JW, Kee Y, Scheller RH (1996) The mammalian brain rsec6/8 complex. Neuron 17 (6):1209-1219 [PubMed: 8982167]

4. Taheri-Talesh N, Horio T, Araujo-Bazan L, Dou X, Espeso EA, Penalva MA, Osmani SA, Oakley BR (2008) The tip growth apparatus of Aspergillus nidulans. Molecular biology of the cell 19 (4): 1439-1449 [PubMed: 18216285]

5. Wu B, Guo W (2015) The Exocyst at a Glance. Journal of cell science 128 (16):2957-2964. doi: 10.1242/jcs.156398 [PubMed: 26240175]

6. Grindstaff KK, Yeaman C, Anandasabapathy N, Hsu SC, Rodriguez-Boulan E, Scheller RH, Nelson WJ (1998) Sec6/8 complex is recruited to cell-cell contacts and specifies transport vesicle delivery to the basal-lateral membrane in epithelial cells. Cell 93 (5):731-740 [PubMed: 9630218]

7. Lavy M, Bloch D, Hazak O, Gutman I, Poraty L, Sorek N, Sternberg H, Yalovsky S (2007) A Novel ROP/RAC effector links cell polarity, root-meristem maintenance, and vesicle trafficking. Curr Biol 17 (11):947-952 [PubMed: 17493810]

8. Zuo X, Zhang J, Zhang Y, Hsu SC, Zhou D, Guo W (2006) Exo70 interacts with the Arp2/3 complex and regulates cell migration. Nature cell biology 8 (12):1383-1388 [PubMed: 17086175]

9. Vega IE, Hsu SC (2001) The exocyst complex associates with microtubules to mediate vesicle targeting and neurite outgrowth. J Neurosci 21 (11):3839-3848 [PubMed: 11356872]

10. Brennwald P (2013) Membrane traffic: the exocyst meets the cell cycle. Curr Biol 23 (18):R838840. doi:10.1016/j.cub.2013.08.007 [PubMed: 24070443]

11. Bodemann BO, Orvedahl A, Cheng T, Ram RR, Ou YH, Formstecher E, Maiti M, Hazelett CC, Wauson EM, Balakireva M, Camonis JH, Yeaman C, Levine B, White MA (2011) RalB and the exocyst mediate the cellular starvation response by direct activation of autophagosome assembly. Cell 144 (2):253-267 [PubMed: 21241894]

12. Zuo X, Guo W, Lipschutz JH (2009) The exocyst protein Sec10 is necessary for primary ciliogenesis and cystogenesis in vitro. Molecular biology of the cell 20 (10):2522-2529 [PubMed: 19297529]

13. Seixas C, Choi SY, Polgar N, Umberger NL, East MP, Zuo X, Moreiras H, Ghossoub R, Benmerah A, Kahn RA, Fogelgren B, Caspary T, Lipschutz JH, Barral DC (2016) Arl13b and the exocyst interact synergistically in ciliogenesis. Molecular biology of the cell 27 (2):308-320 [PubMed: 26582389]

14. Lipschutz JH, Mostov KE (2002) Exocytosis: the many masters of the exocyst. Curr Biol 12 (6):R212-214 [PubMed: 11909549]

15. Zhang X, Orlando K, He B, Xi F, Zhang J, Zajac A, Guo W (2008) Membrane association and functional regulation of Sec3 by phospholipids and Cdc42. The Journal of cell biology 180 (1): 145-158. doi:10.1083/jcb.200704128 [PubMed: 18195105]

16. Zuo X, Fogelgren B, Lipschutz JH (2011) The small GTPase Cdc42 is necessary for primary ciliogenesis in renal tubular epithelial cells. The Journal of biological chemistry 286 (25):2246922477. doi:10.1074/jbc.M111.238469 [PubMed: 21543338]

17. Fogelgren B, Polgar N, Lui VH, Lee AJ, Tamashiro KK, Napoli JA, Walton CB, Zuo X, Lipschutz JH (2015) Urothelial Defects from Targeted Inactivation of Exocyst Sec10 in Mice Cause Ureteropelvic Junction Obstructions. PloS one 10 (6):e0129346 [PubMed: 26046524] 
18. Choi SY, Chacon-Heszele MF, Huang L, McKenna S, Wilson FP, Zuo X, Lipschutz JH (2013) Cdc42 deficiency causes ciliary abnormalities and cystic kidneys. J Am Soc Nephrol 24 (9):14351450. doi:10.1681/ASN.2012121236 [PubMed: 23766535]

19. Moritz OL, Tam BM, Hurd LL, Peranen J, Deretic D, Papermaster DS (2001) Mutant rab8 Impairs docking and fusion of rhodopsin-bearing post-Golgi membranes and causes cell death of transgenic Xenopus rods. Molecular biology of the cell 12 (8):2341-2351 [PubMed: 11514620]

20. Nachury MV, Loktev AV, Zhang Q, Westlake CJ, Peranen J, Merdes A, Slusarski DC, Scheller RH, Bazan JF, Sheffield VC, Jackson PK (2007) A core complex of BBS proteins cooperates with the GTPase Rab8 to promote ciliary membrane biogenesis. Cell 129 (6):1201-1213. doi:10.1016/ j.cell.2007.03.053 [PubMed: 17574030]

21. Anttonen T, Kirjavainen A, Belevich I, Laos M, Richardson WD, Jokitalo E, Brakebusch C, Pirvola U (2012) Cdc42-dependent structural development of auditory supporting cells is required for wound healing at adulthood. Scientific reports 2:978. doi:10.1038/srep00978 [PubMed: 23248743]

22. Heidrych P, Zimmermann U, Bress A, Pusch CM, Ruth P, Pfister M, Knipper M, Blin N (2008) Rab8b GTPase, a protein transport regulator, is an interacting partner of otoferlin, defective in a human autosomal recessive deafness form. Human molecular genetics 17 (23):3814-3821. doi: 10.1093/hmg/ddn279 [PubMed: 18772196]

23. Kirjavainen A, Laos M, Anttonen T, Pirvola U (2015) The Rho GTPase Cdc42 regulates hair cell planar polarity and cellular patterning in the developing cochlea. Biology open 4 (4):516-526 [PubMed: 25770185]

24. Roux I, Safieddine S, Nouvian R, Grati M, Simmler MC, Bahloul A, Perfettini I, Le Gall M, Rostaing P, Hamard G, Triller A, Avan P, Moser T, Petit C (2006) Otoferlin, defective in a human deafness form, is essential for exocytosis at the auditory ribbon synapse. Cell 127 (2):277-289. doi:10.1016/j.cell.2006.08.040 [PubMed: 17055430]

25. Blake JA, Eppig JT, Kadin JA, Richardson JE, Smith CL, Bult CJ, the Mouse Genome Database G (2017) Mouse Genome Database (MGD)-2017: community knowledge resource for the laboratory mouse. Nucleic Acids Res 45 (D1):D723-D729. doi:10.1093/nar/gkw1040 [PubMed: 27899570]

26. Guo W, Roth D, Walch-Solimena C, Novick P (1999) The exocyst is an effector for Sec4p, targeting secretory vesicles to sites of exocytosis. The EMBO journal 18 (4):1071-1080 [PubMed: 10022848]

27. Seo YJ, Ko SB, Ha TH, Gong TH, Bong JP, Park DJ, Park SY (2015) Association of hearing impairment with chronic kidney disease: a cross-sectional study of the Korean general population. BMC nephrology 16:154 [PubMed: 26377178]

28. Lin C, Hsu HT, Lin YS, Weng SF (2013) Increased risk of getting sudden sensorineural hearing loss in patients with chronic kidney disease: a population-based cohort study. Laryngoscope 123 (3):767-773. doi:10.1002/lary.23669 [PubMed: 22927011]

29. Norgett EE, Golder ZJ, Lorente-Canovas B, Ingham N, Steel KP, Karet Frankl FE (2012) Atp6v0a4 knockout mouse is a model of distal renal tubular acidosis with hearing loss, with additional extrarenal phenotype. Proceedings of the National Academy of Sciences of the United States of America 109 (34):13775-13780. doi:10.1073/pnas.1204257109 [PubMed: 22872862]

30. Yang H, Gan J, Xie X, Deng M, Feng L, Chen X, Gao Z, Gan L (2010) Gfi1-Cre knock-in mouse line: A tool for inner ear hair cell-specific gene deletion. Genesis 48 (6):400-406. doi:10.1002/ dvg.20632 [PubMed: 20533399]

31. Kim MA, Cho HJ, Bae SH, Lee B, Oh SK, Kwon TJ, Ryoo ZY, Kim HY, Cho JH, Kim UK, Lee KY (2016) Methionine sulfoxide reductase B3-targeted in utero gene therapy rescues hearing function in a mouse model of congenital sensorineural hearing loss. Antioxidants $\&$ redox signaling 24 (11):590-602 [PubMed: 26649646]

32. Kwon TJ, Oh SK, Kim YR, Kim MA, Lee B, Choi KS, Lee J, Kim UK, Lee KY (2014) Methionine sulfoxide reductase A, B1 and B2 are likely to be involved in the protection against oxidative stress in the inner ear. Cells, tissues, organs 199 (4):294-300 [PubMed: 25531578]

33. Tarchini B, Jolicoeur C, Cayouette M (2013) A molecular blueprint at the apical surface establishes planar asymmetry in cochlear hair cells. Developmental cell 27 (1):88-102 [PubMed: 24135232]

34. Ohyama T, Groves AK (2004) Generation of Pax2-Cre mice by modification of a Pax2 bacterial artificial chromosome. Genesis 38 (4):195-199 [PubMed: 15083520] 
35. Hebert JM, McConnell SK (2000) Targeting of cre to the Foxg1 (BF-1) locus mediates loxP recombination in the telencephalon and other developing head structures. Developmental biology 222 (2):296-306 [PubMed: 10837119]

36. Madisen L, Zwingman TA, Sunkin SM, Oh SW, Zariwala HA, Gu H, Ng LL, Palmiter RD, Hawrylycz MJ, Jones AR, Lein ES, Zeng H (2010) A robust and high-throughput Cre reporting and characterization system for the whole mouse brain. Nature neuroscience 13 (1):133-140 [PubMed: 20023653]

37. Shi F, Hu L, Edge AS (2013) Generation of hair cells in neonatal mice by beta-catenin overexpression in Lgr5-positive cochlear progenitors. Proceedings of the National Academy of Sciences of the United States of America 110 (34):13851-13856. doi:10.1073/pnas.1219952110 [PubMed: 23918377]

38. Duncan JS, Fritzsch B (2013) Continued Expression of GATA3 Is Necessary for Cochlear Neurosensory Development. PloS one 8 (4):e62046. doi:10.1371/journal.pone.0062046 [PubMed: 23614009]

39. Buret L, Rebillard G, Brun E, Angebault C, Pequignot M, Lenoir M, Do-Cruzeiro M, Tournier E, Cornille K, Saleur A, Gueguen N, Reynier P, Amati-Bonneau P, Barakat A, Blanchet C, Chinnery P, Yu-Wai-Man P, Kaplan J, Roux AF, Van Camp G, Wissinger B, Boespflug-Tanguy O, Giraudet F, Puel JL, Lenaers G, Hamel C, Delprat B, Delettre C (2016) Loss of function of in mice induces deafness and cochlear outer hair cells' degeneration. Cell Death Discov 2:16017. doi:10.1038/ cddiscovery.2016.17 [PubMed: 27275396]

40. Balakireva M, Rosse C, Langevin J, Chien YC, Gho M, Gonzy-Treboul G, Voegeling-Lemaire S, Aresta S, Lepesant JA, Bellaiche Y, White M, Camonis J (2006) The Ral/exocyst effector complex counters c-Jun N-terminal kinase-dependent apoptosis in Drosophila melanogaster. Molecular and cellular biology 26 (23):8953-8963 [PubMed: 17000765]

41. Tanaka T, Kikuchi N, Goto K, Iino M (2016) Sec6/8 regulates Bcl-2 and Mcl-1, but not Bcl-xl, in malignant peripheral nerve sheath tumor cells. Apoptosis 21 (5):594-608. doi:10.1007/ s10495-016-1230-9 [PubMed: 26892009]

42. Polgar N, Lee AJ, Lui VH, Napoli JA, Fogelgren B (2015) The exocyst gene Sec10 regulates renal epithelial monolayer homeostasis and apoptotic sensitivity. American journal of physiology 309 (3):C190-201. doi:10.1152/ajpcell.00011.2015 [PubMed: 26040895]

43. Ben-Yosef T, Belyantseva IA, Saunders TL, Hughes ED, Kawamoto K, Van Itallie CM, Beyer LA, Halsey K, Gardner DJ, Wilcox ER, Rasmussen J, Anderson JM, Dolan DF, Forge A, Raphael Y, Camper SA, Friedman TB (2003) Claudin 14 knockout mice, a model for autosomal recessive deafness DFNB29, are deaf due to cochlear hair cell degeneration. Human molecular genetics 12 (16):2049-2061 [PubMed: 12913076]

44. Nakano Y, Kim SH, Kim HM, Sanneman JD, Zhang Y, Smith RJ, Marcus DC, Wangemann P, Nessler RA, Banfi B (2009) A claudin-9-based ion permeability barrier is essential for hearing. PLoS genetics 5 (8):e1000610 [PubMed: 19696885]

45. Kitajiri S, Katsuno T, Sasaki H, Ito J, Furuse M, Tsukita S (2014) Deafness in occludin-deficient mice with dislocation of tricellulin and progressive apoptosis of the hair cells. Biology open 3 (8): 759-766 [PubMed: 25063198]

46. Nayak G, Lee SI, Yousaf R, Edelmann SE, Trincot C, Van Itallie CM, Sinha GP, Rafeeq M, Jones SM, Belyantseva IA, Anderson JM, Forge A, Frolenkov GI, Riazuddin S (2013) Tricellulin deficiency affects tight junction architecture and cochlear hair cells. The Journal of clinical investigation 123 (9):4036-4049 [PubMed: 23979167]

47. Gulley RL, Reese TS (1976) Intercellular junctions in the reticular lamina of the organ of Corti. Journal of neurocytology 5 (4):479-507 [PubMed: 993823]

48. Zenner HP, Reuter G, Zimmermann U, Gitter AH, Fermin C, LePage EL (1994) Transitory endolymph leakage induced hearing loss and tinnitus: depolarization, biphasic shortening and loss of electromotility of outer hair cells. Eur Arch Otorhinolaryngol 251 (3):143-153 [PubMed: 8080633]

49. Morozko EL, Nishio A, Ingham NJ, Chandra R, Fitzgerald T, Martelletti E, Borck G, Wilson E, Riordan GP, Wangemann P, Forge A, Steel KP, Liddle RA, Friedman TB, Belyantseva IA (2015) ILDR1 null mice, a model of human deafness DFNB42, show structural aberrations of tricellular 
tight junctions and degeneration of auditory hair cells. Human molecular genetics 24 (3):609-624 [PubMed: 25217574]

50. Blankenship JT, Fuller MT, Zallen JA (2007) The Drosophila homolog of the Exo84 exocyst subunit promotes apical epithelial identity. Journal of cell science 120 (Pt 17):3099-3110 [PubMed: 17698923]

51. Hazelett CC, Sheff D, Yeaman C (2011) RalA and RalB differentially regulate development of epithelial tight junctions. Molecular biology of the cell 22 (24):4787-4800 [PubMed: 22013078]

52. Muslin AJ, Tanner JW, Allen PM, Shaw AS (1996) Interaction of 14-3-3 with signaling proteins is mediated by the recognition of phosphoserine. Cell 84 (6):889-897 [PubMed: 8601312]

53. Leto D, Uhm M, Williams A, Chen XW, Saltiel AR (2013) Negative regulation of the RalGAP complex by 14-3-3. The Journal of biological chemistry 288 (13):9272-9283. doi:10.1074/ jbc.M112.426106 [PubMed: 23386617]

54. Vasara T, Keranen S, Penttila M, Saloheimo M (2002) Characterisation of two 14-3-3 genes from Trichoderma reesei: interactions with yeast secretory pathway components. Biochim Biophys Acta 1590 (1-3):27-40 [PubMed: 12063166]

55. Murthy M, Garza D, Scheller RH, Schwarz TL (2003) Mutations in the exocyst component Sec5 disrupt neuronal membrane traffic, but neurotransmitter release persists. Neuron 37 (3):433-447 [PubMed: 12575951]

56. Hazuka CD, Foletti DL, Hsu SC, Kee Y, Hopf FW, Scheller RH (1999) The sec6/8 complex is located at neurite outgrowth and axonal synapse-assembly domains. J Neurosci 19 (4):1324-1334 [PubMed: 9952410]

57. Lalli G (2009) RalA and the exocyst complex influence neuronal polarity through PAR-3 and aPKC. Journal of cell science 122 (Pt 10):1499-1506 [PubMed: 19383721]

58. Puel JL, Ruel J, Gervais d'Aldin C, Pujol R (1998) Excitotoxicity and repair of cochlear synapses after noise-trauma induced hearing loss. Neuroreport 9 (9):2109-2114 [PubMed: 9674603]

59. Buniello A, Ingham NJ, Lewis MA, Huma AC, Martinez-Vega R, Varela-Nieto I, Vizcay-Barrena G, Fleck RA, Houston O, Bardhan T, Johnson SL, White JK, Yuan H, Marcotti W, Steel KP (2016) Wbp2 is required for normal glutamatergic synapses in the cochlea and is crucial for hearing. EMBO Mol Med 8 (3):191-207. doi:10.15252/emmm.201505523 [PubMed: 26881968]

60. Kujawa SG, Liberman MC (2009) Adding insult to injury: cochlear nerve degeneration after "temporary" noise-induced hearing loss. J Neurosci 29 (45):14077-14085. doi:10.1523/ JNEUROSCI.2845-09.2009 [PubMed: 19906956]

61. Dulubova I, Khvotchev M, Liu S, Huryeva I, Sudhof TC, Rizo J (2007) Munc18-1 binds directly to the neuronal SNARE complex. Proceedings of the National Academy of Sciences of the United States of America 104 (8):2697-2702 [PubMed: 17301226]

62. Morgera F, Sallah MR, Dubuke ML, Gandhi P, Brewer DN, Carr CM, Munson M (2012) Regulation of exocytosis by the exocyst subunit Sec6 and the SM protein Sec1. Molecular biology of the cell 23 (2):337-346. doi:10.1091/mbc.E11-08-0670 [PubMed: 22114349]

63. Seal RP, Akil O, Yi E, Weber CM, Grant L, Yoo J, Clause A, Kandler K, Noebels JL, Glowatzki E, Lustig LR, Edwards RH (2008) Sensorineural deafness and seizures in mice lacking vesicular glutamate transporter 3. Neuron 57 (2):263-275 [PubMed: 18215623]

64. Gierut JJ, Jacks TE, Haigis KM (2014) Strategies to achieve conditional gene mutation in mice. Cold Spring Harbor protocols 2014 (4):339-349 [PubMed: 24692485] 

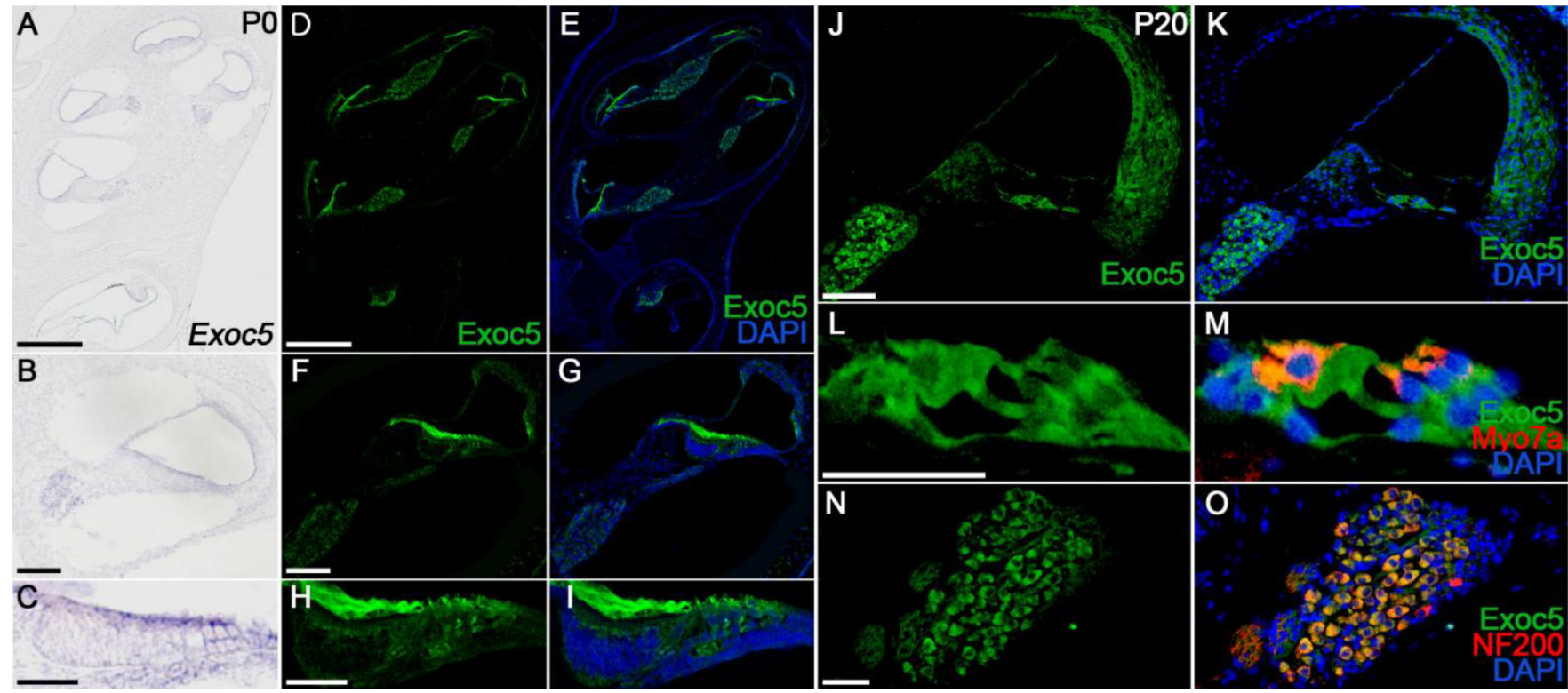

Fig. 1. Spatial pattern of EXOC5 expression in the inner ear.

(A-I) Expression pattern of EXOC5 was examined by in situ hybridization (A-C) and immunohistochemistry (D-I) at P0. The mRNA (violet) and protein (green) expression levels of EXOC5 were compared between the whole inner ear (A, D, and E), middle turn of the cochlea (B, F, and $\mathrm{G})$ and the organ of Corti (C, H, and I). (J-O) EXOC5 immunohistochemistry was performed in the middle turn of the cochlea at P20. EXOC5 expression (green) was observed in both the Organ of Corti ( $\mathrm{L}$ and $\mathrm{M})$ and spiral ganglion ( $\mathrm{N}$ and O). Hair cells and spiral ganglions were labeled with Myo7a (M, red) and NF200 (O, red), respectively. Nuclei were counterstained with DAPI (blue). Scale bars, $200 \mu \mathrm{m}$ in (A, $\mathrm{D}, \mathrm{E}), 50 \mu \mathrm{m}$ in (B, F, G, J, K), $20 \mu \mathrm{m}$ in $(\mathrm{C}, \mathrm{H}, \mathrm{I})$, and $25 \mu \mathrm{m}$ in (L-O). 

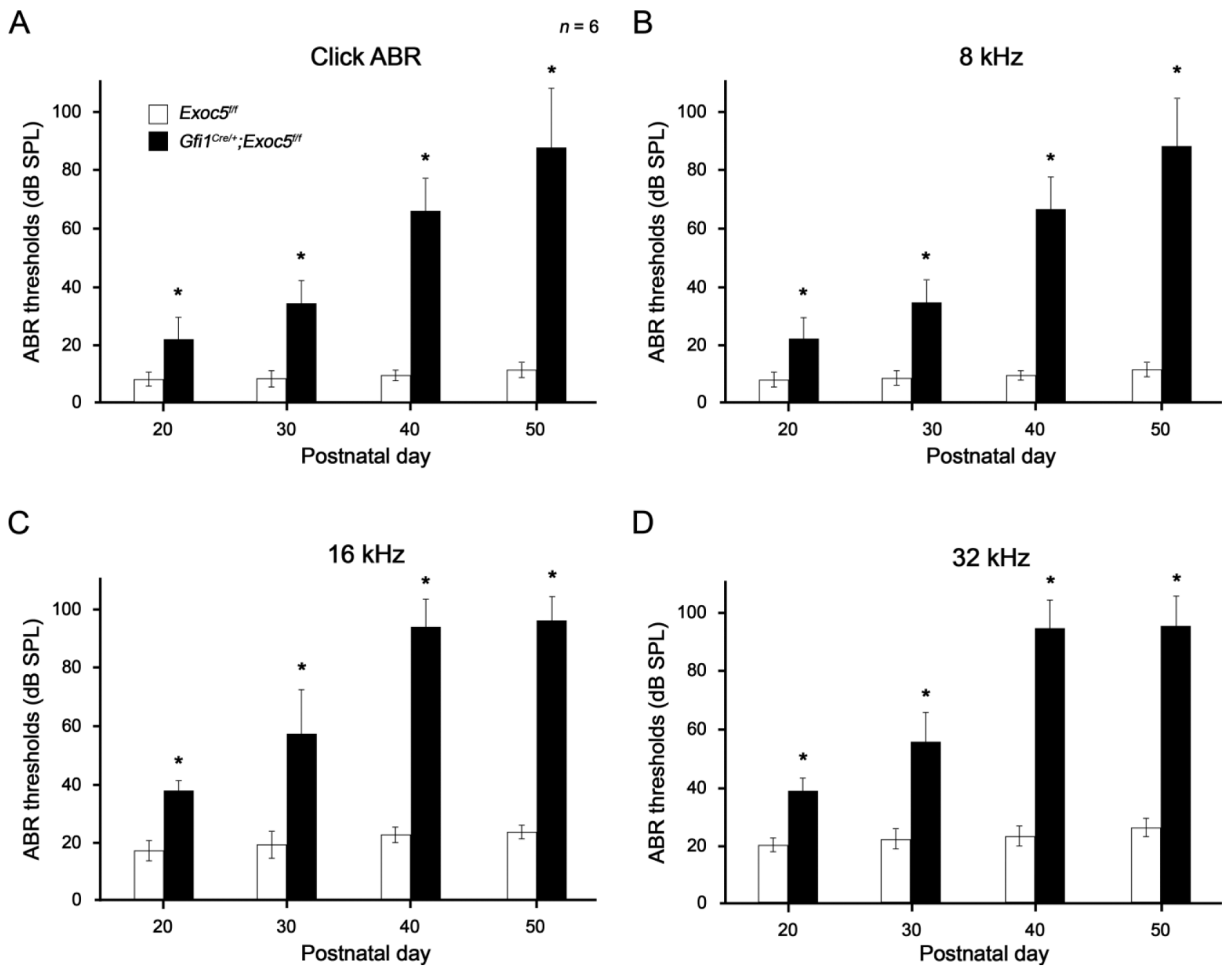

Fig. 2. Progressive hearing loss of $\mathrm{Gfil}^{\mathrm{Cre} /+}$;Exoc $5^{\mathrm{f} / \mathrm{f}}$ mice.

The click (A) and tone burst $8 \mathrm{kHz}(\mathrm{B}), 16 \mathrm{kHz}$ (C), and $32 \mathrm{kHz}$ (D) ABR thresholds were compared between $E_{x O c 5^{f / f}}$ (white rectangle) and $G f i 1^{C r e / t} ; E x O c 5^{f / f}$ mice (black rectangle) at differential postnatal days. The data are shown as the mean $\pm \mathrm{SD}\left(n=6\right.$ for each group, ${ }^{*} P$ $<0.05)$. 

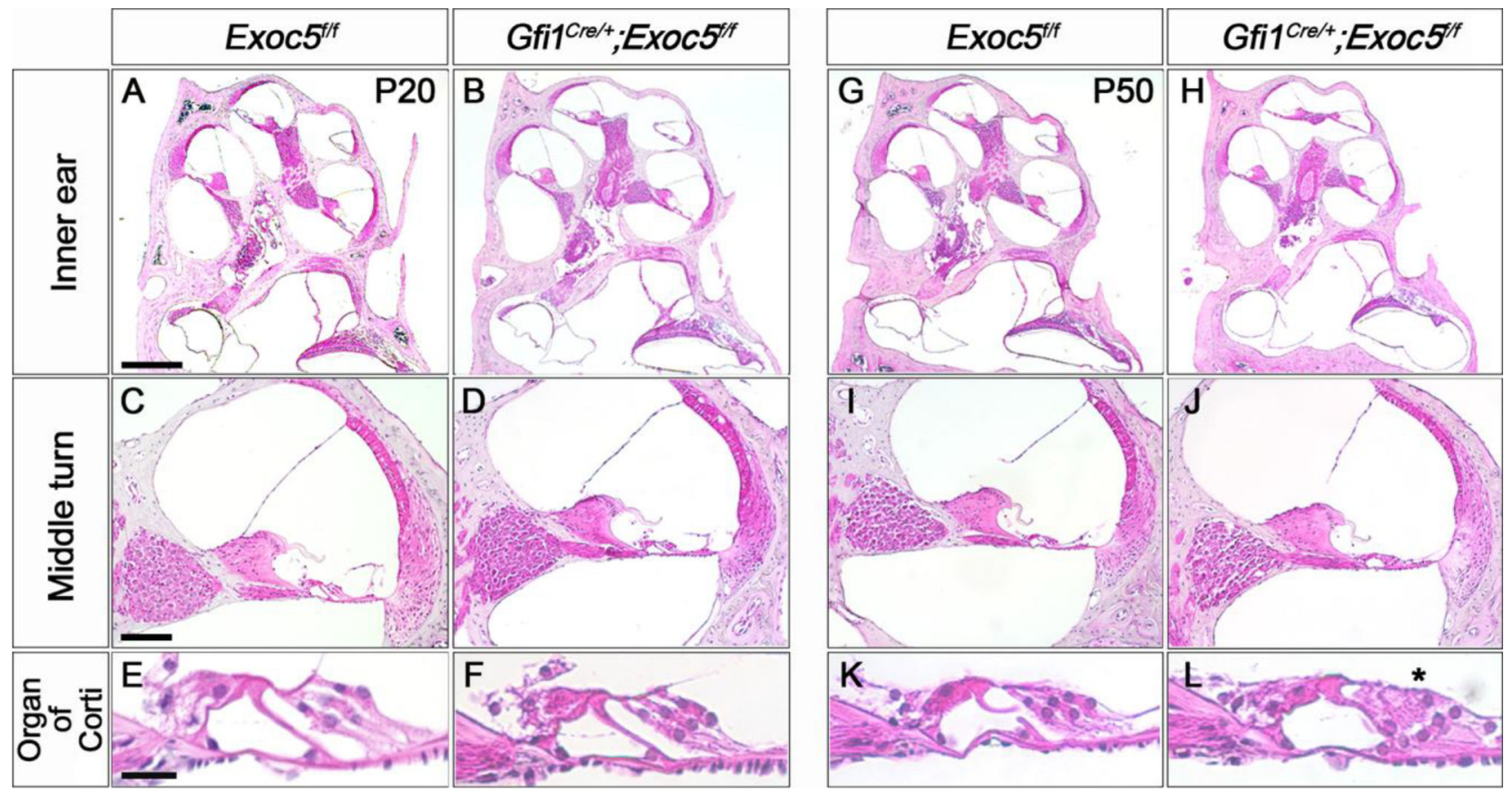

Fig. 3. Histological evaluation of the inner ear of $\mathrm{Gfil}^{\mathrm{Cre} /+}$;Exoc $5^{f / f}$ mice.

H\&E staining was performed on the inner ear sections of Exoc $5^{f / f}$ and $G f i 1^{C r e / t} ; E x O c 5^{f / f}$ mice at P20 (A-F) and P50 (G-L). (A, B, G, and H) Whole inner ear. (C, D, I, and J) Middle turn of the cochlea. (E, F, K, and L) High magnification of the organ of Corti. Asterisk indicate degenerating outer hair cells. Scale bars, $200 \mu \mathrm{m}$ in (A, B, G, H), $50 \mu \mathrm{m}$ in (C, D, I, $\mathrm{J})$, and $10 \mu \mathrm{m}$ in $(\mathrm{E}, \mathrm{F}, \mathrm{K}, \mathrm{L})$. 

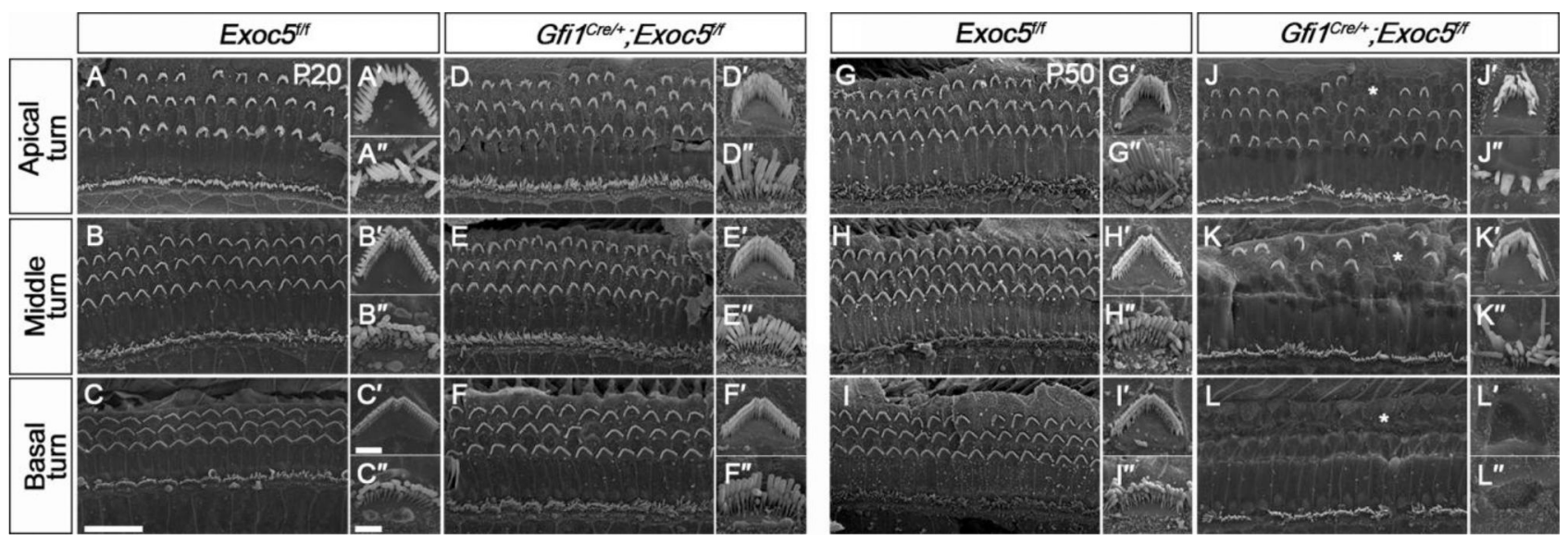

Fig. 4. Ultrastructural evaluation of the organ of Corti and stereocilia of hair cells in GfiI $^{\mathrm{Cre} /+} ;$ Exoc $^{\text {f/f }}$ mice. $^{-}$

The ultrastructure of stereociliary bundles from Exoc $5^{f / f}$ and $G f i 1^{C r e / t} ; E x o c 5^{f / f}$ mice was analyzed using SEM at P20 (A-F, $A^{\prime}-F^{\prime}$, and $\left.A^{\prime \prime}-F^{\prime \prime}\right)$ and P50 (G-L, $G^{\prime}-L^{\prime}$, and $\left.G^{\prime \prime}-L^{\prime \prime}\right)$. (A-L) The Organ of Corti. ( $\left.\mathrm{A}^{\prime}-\mathrm{L}^{\prime}\right)$ High magnification of an outer hair cell $(\mathrm{OHC})$. ( $\mathrm{A}^{\prime \prime}-\mathrm{L}$ ") High magnification of an inner hair cell (IHC). Abnormal arrangement of rows of OHCs are indicated by asterisks. Scale bars, $15 \mu \mathrm{m}$ in (A-L) and $2 \mu \mathrm{m}$ in $\left(\mathrm{A}^{\prime}-\mathrm{L}^{\prime}\right.$ and $\left.\mathrm{A}^{\prime \prime}-\mathrm{L}^{\prime \prime}\right)$. 


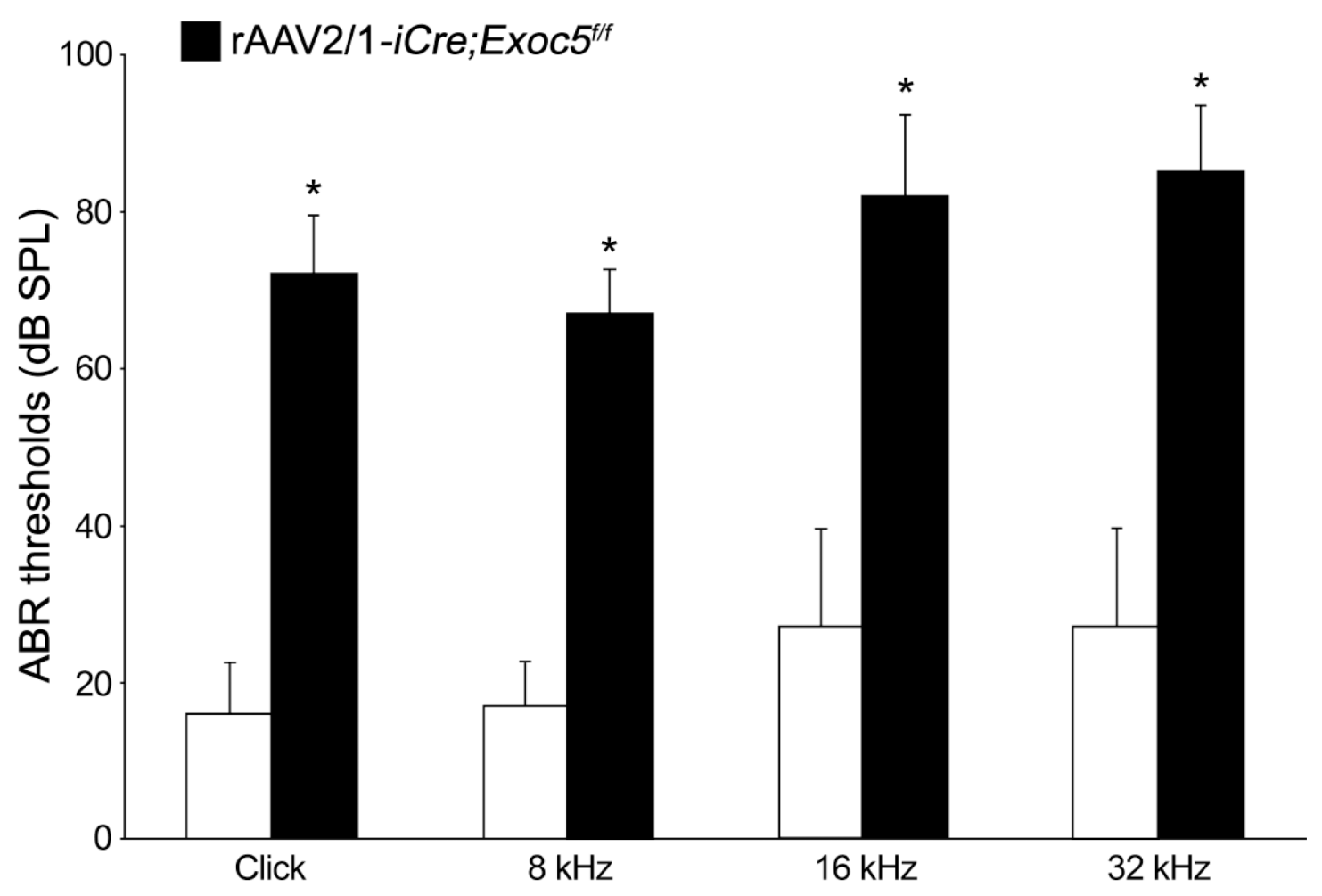

Fig. 5. Profound hearing loss of rAAV2/1-iCre;Exoc $5^{f / f}$ mice at P20.

The click and tone burst $(8,16$, and $32 \mathrm{kHz})$ ABR thresholds of rAAV2/1-iCre;Exoc $5^{f / f}$ mice were measured in rAAV2/1-iCre non-injected inner ear (white) and rAAV2/1-iCre-injected inner ear (black). The data are shown as the mean $\pm \operatorname{SD}(n=5$ for each group, $* P<0.001)$. 


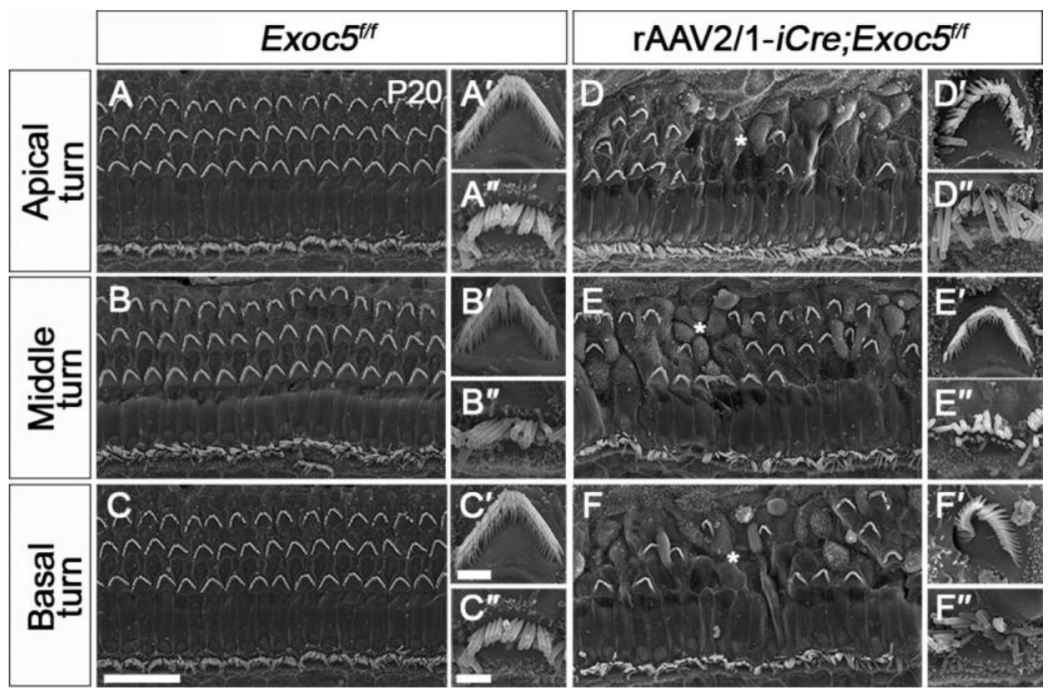

Fig. 6. Ultrastructural evaluation of the organ of Corti and stereocilia of hair cells in rAAV2/1iCre;Exoc $5^{\text {flf }}$ mice.

Morphological changes in hair cells and stereocilia were analyzed by SEM in rAAV2/1-iCre non-injected inner ear $\left(\right.$ Exoc5 $\left.5^{f / f}\right)$ and rAAV2/1-iCre-injected inner ear (rAAV2/1-

iCre;Exoc5 $\left.{ }^{f / f}\right)$ at P20. (A-F) The Organ of Corti. $\left(\mathrm{A}^{\prime}-\mathrm{F}^{\prime}\right)$ High magnification of an outer hair cell $(\mathrm{OHC}) .\left(\mathrm{A}^{\prime \prime}-\mathrm{F}^{\prime \prime}\right)$ High magnification of an inner hair cell (IHC). Asterisks indicate abnormal arrangement of rows of OHC. Scale bars, $15 \mu \mathrm{m}$ in $(\mathrm{A}-\mathrm{F})$ and $2 \mu \mathrm{m}$ in $\left(\mathrm{A}^{\prime}-\mathrm{F}^{\prime}, \mathrm{A}^{\prime \prime}\right.$ $\left.\mathrm{F}^{\prime \prime}\right)$. 

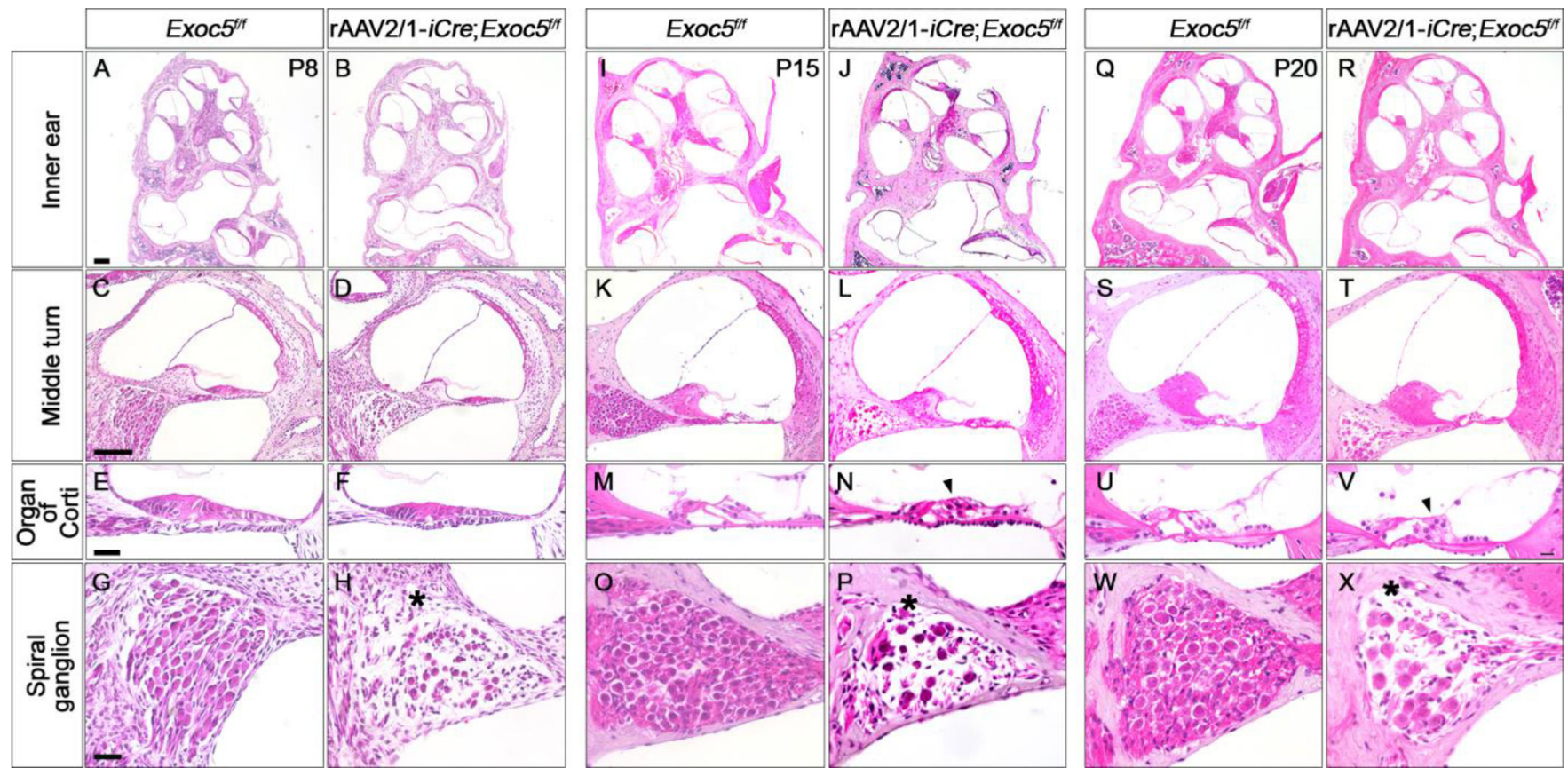

Fig. 7. Histological evaluation of the inner ear of rAAV2/1-iCre;Exoc $5^{f / f}$ mice.

Morphological changes in the inner ear were examined by H\&E staining in $\mathrm{AAAV} 2 / 1-i C r e$ non-injected inner ear $\left(E x O c 5^{f / f}\right)$ and rAAV2/1-iCre-injected inner ear (rAAV2/1-

iCre;Exoc fff $^{f /}$ at P8 (A-H), P15 (I-P), and P20 (Q-X). (A, B, I, J, Q, and R) Whole inner ear. (C, D, K, L, S, and T) Middle turn of the cochlea. (E, F, M, N, U, and V) High magnification of organ of Corti. (G, H, O, P, W, and X) High magnification of a spiral ganglion. Arrow heads and asterisks indicate degeneration of hair cells and spiral ganglions, respectively. Scale bars, $200 \mu \mathrm{m}$ in (A, B, I, J, Q, R), $100 \mu \mathrm{m}$ in (C, D, K, L, S, T), and $25 \mu \mathrm{m}$ in (E-H, M$\mathrm{P}, \mathrm{U}-\mathrm{X})$. 


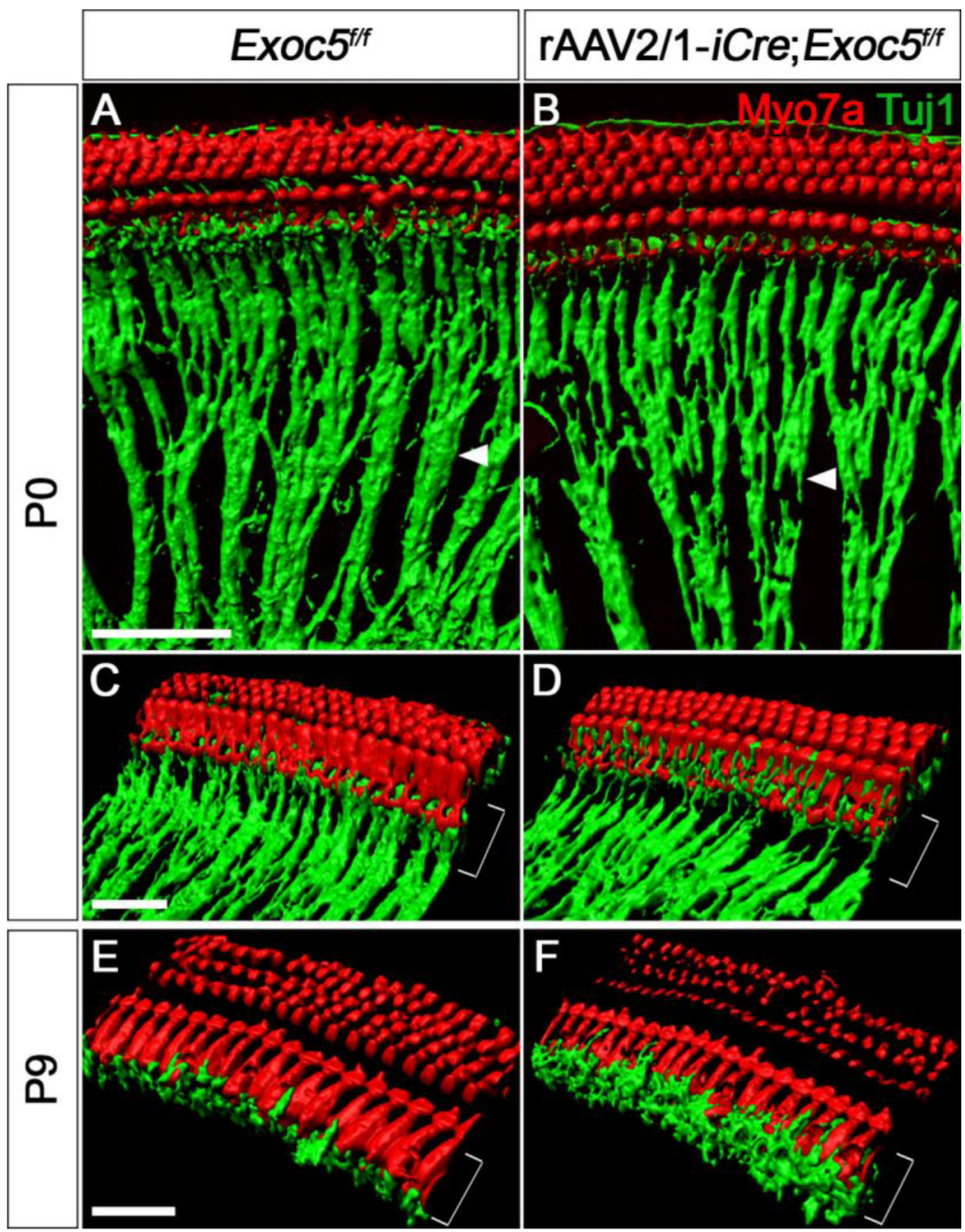

Fig. 8. Diminished afferent innervation of spiral ganglion neurites in rAAV2/1-iCre;Exoc $5^{f / f}$ mice during the early postnatal period.

$3 \mathrm{D}$ renderings of confocal z-stacks were acquired from whole-mounted rAAV2/1-iCre noninjected $\left(\right.$ Exoc5 $\left.5^{f / f}\right)$ and rAAV2/1-iCre-injected inner ear (rAAV2/1-iCre;Exoc $\left.5^{f / f}\right)$. Hair cells and neuronal fibers were stained for Myo7a (red) and TuJ1 (green) at P0 (A-D) and P9 (E and F). Degeneration of neurite outgrowth (arrow heads) and misrouted nerve fibers (square brackets) are shown in rAAV2/1-iCre; $E x o c 5^{f / f}$ mice. Scale bars, $30 \mu \mathrm{m}$. 
A

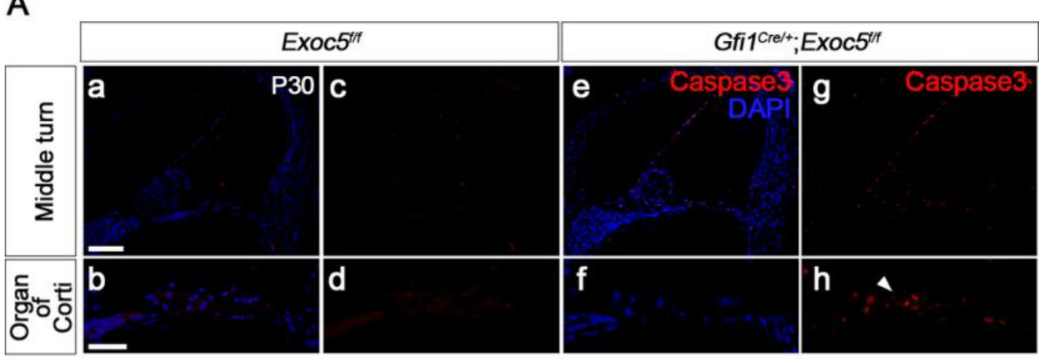

B

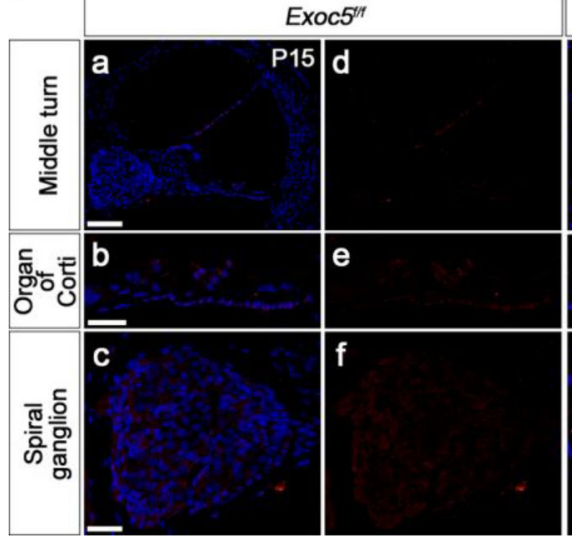

rAAV2/1-iCre;Exoc5"

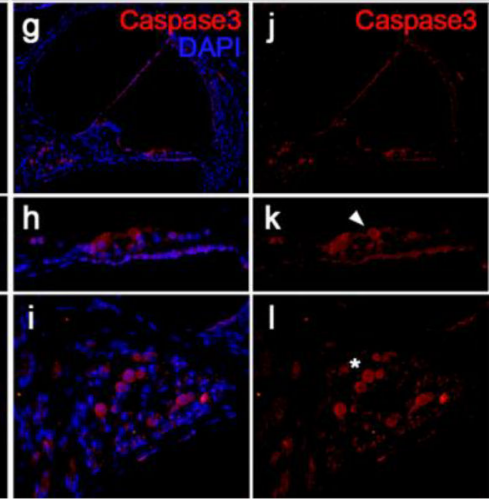

Fig. 9. Apoptosis in the sensory epithelium of $\mathrm{Gfil}^{\mathrm{Cre} /+} ;{ }^{E x o c} 5^{f / f}$ and rAAV2/1-iCre;Exoc $5^{f / f}$ mice.

Apoptosis was examined by Caspase 3 immunostaining in the inner ear of Gfi $^{C r e}{ }^{+}$;Exoc $5^{f / f}$ mice at P30 (A) and rAAV2/1-iCre;Exoc5 $5^{f / f}$ mice at P15 (B). Activated Caspase3-positive cells were labeled with Alexa Fluor® 555. Caspase3 activation in hair cells and spiral ganglions are indicated by arrow heads and asterisks, respectively. Nuclei were counterstained with DAPI (blue). Scale bars, $100 \mu \mathrm{m}$ in (middle turn panels) and $25 \mu \mathrm{m}$ in (organ of Corti and spiral ganglion panels). 